\title{
Study on Treatment of Loess Landslide Based on Nanosilica and Fly Ash Composite Stabilizer Filling Fissures
}

\author{
Jiulong Gao, Jiading Wang $(\mathbb{D}$, Yao Wei, Shaotong Jiao, Meng Jing, Jialing Gao, \\ and Cong Wang \\ Department of Geology, State Key Laboratory of Continental Dynamics, Northwest University, Xi'an 710069, China \\ Correspondence should be addressed to Jiading Wang; wangjiading029@163.com
}

Received 29 May 2020; Revised 15 July 2020; Accepted 16 August 2020; Published 31 August 2020

Academic Editor: Chong Xu

Copyright ( $\odot 2020$ Jiulong Gao et al. This is an open access article distributed under the Creative Commons Attribution License, which permits unrestricted use, distribution, and reproduction in any medium, provided the original work is properly cited.

\begin{abstract}
Frequent occurrence of landslides has seriously threatened the infrastructural projects in the Loess Plateau, China. At the beginning, with development of the landslide, several fissures were generated along the internal weak surface. Then, under the constant influence of rainfall and irrigation, the fissures were expanded and connected, which formed a consecutive sliding surface, consequently leading to the occurrence of the landslide. Therefore, the key to treat the landslide is to prevent the expansion and connection of fissures in the potential slip zone inside the slope. In this paper, an old landslide, which occurred at an early stage of the construction of the Lvliang Airport, was selected as a case study. A new type of grouting material was used to fill the fissures and reinforce the loess in the slip zone, so as to study the effect of material content on the slope stability. With current methods, loess specimens were taken from the slip zone inside the Lvliang Airport slope. Based on the GDS triaxial test system, a series of laboratory tests were performed on the undisturbed loess and the remolded which contained the stabilizer, including triaxial shear tests at constant matric suctions and wetting tests at constant deviator stresses. Moreover, the dichotomy in mathematics was chosen to find the threshold of the material content. The test results showed that the cohesion and the internal friction angle of the loess obviously increased after grouting. The failure behaviour of the loess along the wetting path was dependent on the material ratio and the stress level. Meanwhile, the critical state line of the slope, grouted with materials of different ratios, was compared by fitting the regression equation. It was found that the threshold value of the stabilizer content was between $15 \%$ and $20 \%$, which was the most suitable ratio for improving slope stability with relatively lower cost.
\end{abstract}

\section{Introduction}

Recently, in order to meet the needs of economic development and population growth, a series of engineering projects have been carried out in the Loess Plateau, China [1]. It has become a tendency for urban construction to create more land by flattening hill and filling gully, due to the crisscrossed formed by gullies and few land resources in this area. However, unreasonable excavation, land-filling, and other human activities lead to frequent landslides, which seriously affects the project construction [2]. Rainfall and irrigation are the main triggering factors of loess landslides [3-6]. In the case of rainwater infiltration, the increase of the moisture content of unsaturated soil leads to the increase of pore water pressure and the decrease of matric suction. Both of these factors move the soil stress states towards its theoretical failure line [7-10]. Moreover, the fissures in the shallow slope enhance the infiltration capacity of the soil and make the slope evolve towards an unstable state [11, 12]. Rosone et al. [13] found that a prominent feature of the fissured clays' outcrop slope is that it is extremely prone to landslides. The increase in pore water pressure caused by rainfall may cause the soil to change from static or low-speed creep to accelerated sliding. Lvliang Airport is a typical loess filling engineering, which is located in $20.5 \mathrm{~km}$ north of Lvliang City in Shanxi Province, China. By the end of March 2012, 14 fissures were discovered in the loess slope with a length of more than $7.5 \mathrm{~m}$ [14]. There occurred a large landslide during the construction of Lvliang Airport. In the past research, the water-induced mechanism of the old loess 
landslide was obtained by laboratory tests and field investigation including exploratory wells and boreholes [2]. Previous studies have revealed that before failure, the slope will undergo a series of changes including development of the fissures, softening of the compacted loess, creeping of the slope leading edge and fissuring of the trailing edge, and formation of the through-sliding surface [14]. Therefore, it can be predicted that the occurrence of fissures and the wetting effect of water will lead the landslide to reactivate. On the contrary, the landslide can be effectively treated by filling the fissures and inhibiting its extension, thus avoiding the loss caused by the landslide. A suitable fissure filling material needs to be verified by experiments. In this paper, fly ash and nano- $\mathrm{SiO}_{2}$ mixture were selected as fissure fillers. Fly ash, the degree of resource utilization of which is low, is a kind of industrial waste discharged from coal-fired boilers and power station [15-17]. It has fine particles, stable components, and other good engineering characteristics, including high strength, small compressibility, and good water stability [18]. Reasonable utilization of fly ash is conducive to reducing environmental pollution and engineering cost [18]. Previous studies found that the pozzolanic activity of fly ash is low in the early stage of test [19] and gradually develops in the late stage, while nano- $\mathrm{SiO}_{2}$ is the opposite [20], which can be selected as a complementary material. Nano- $\mathrm{SiO}_{2}$ can improve the physical and mechanical properties of loess by filling large pores and cementing coarse particles [21,22]. And all of these could be mainly attributed to the good pozzolanic and filling effects of nano- $\mathrm{SiO}_{2}[23,24]$. In limited studies, the properties of nano- $\mathrm{SiO}_{2}$ to improve the mechanical properties of soil have been continuously verified $[22,25]$. Compared with traditional chemical additives such as cement and lime, the application of nano- $\mathrm{SiO}_{2}$ in soil improvement greatly reduces the total cost of the stabilizer [26].

Previous research studies mainly focused on mixing the stabilizer with soil to improve the mechanical properties of soil [27-30]. However, in practical application, due to the large scale of the slope in Lvliang Airport, it was not effective to improve soil quality by mixing the stabilizer with soil. Recent studies have shown that the key to treat the slope in Lvliang Airport is to inhibit fissures extension, as a result, this paper focused on the evaluation of slope stability after fissures' filling.

In the past studies of slope stability, a variety of laboratory tests such as model test, numerical simulation, triaxial test, and wetting test have been widely used by scientists from all over the world [10, 31-33]. These studies discussed the relationship between pore water pressure, matric suction, and strength under rainfall infiltration and obtained the failure threshold of the natural slope.

Different from most previous research studies, this paper studies the stability of the loess slope after filling fissures. On the one hand, the fissures treated with filling materials in the loess slope can prevent rainwater infiltration. On the other hand, the pozzolanic reaction between the filling material and the loess improves the mechanical properties of loess from the sliding zone [34]. Two questions arise: does the loess strength of the slope increase after filling fissures?
Whether the improved loess slope can resist wetting-induced slope failure or not? In recent years, researchers have tried to build models for the slope of clayey soil, cohesionless soil, and sandy soil after cement grouting and found that the increase of cohesion and internal friction angle is conducive to the increase of slope stability $[33,35]$. In view of the above findings, rainfall infiltration increases pore water pressure, reducing soil strength. And this failure mechanism will accelerate with the occurrence of fissures [36]. However, the slope with fissures filled may be more resistant to these adverse factors due to the increase of cohesion and internal friction angle. Therefore, the main point is whether there is an appropriate threshold of the stabilizer content, which can increase the cohesion and the internal friction angle of the loess just enough to resist the slope instability caused by the increase of pore water pressure.

Based on the slope of Lvliang Airport, the stability of the slope under the condition of rainwater infiltration was studied before and after filling fissures. Using the GDS triaxial test system, the laboratory tests including triaxial shear tests at constant matric suctions and wetting tests at constant deviator stresses were carried out for the samples with materials of different ratios. These tests aimed to simulate the wetting process of the slope caused by rainfall. On this basis, the failure behaviour of samples along the wetting path before and after being stabilized was compared, and the reinforcement mechanism and feasibility of fissures' filling were analyzed and evaluated.

\section{Data and Methods}

2.1. Study Area and Field Investigation. Lvliang Airport is located in Dawu town, Lvliang City, Shanxi Province, China (Figures 1(a)-1(c)). It is about $9 \mathrm{~km}$ away from the edge of urban planning and about $20.5 \mathrm{~km}$ away from the center of Lvliang city. The terrain undulations are relatively large, with the ridges and hills' district under the central line of the runway as the local watershed. There are nearly 20 dendritic gullies developed on both sides, and the vertical and horizontal cutting depth is $20-100 \mathrm{~m}$. The cross-section of the gullies upstream are mostly in the shape of " $V$," while the downstream gullies are in the shape of " $U$."

The lithology in this area is relatively single, and the site lithology profile can be divided into three units. (1) The top is the early Pleistocene aeolian Malan loess, with a thickness of about 1-16 m. (2) The bedrock consists of Carboniferous mudstone, containing a small amount of sandstone with little fissures. (3) Covering the upper part of the bedrock is Pleistocene aeolian Lishi loess with several palaeosol partings, with a thickness of about 5-32 m.

During the investigation stage, a large loess landslide was found on the southwest side of the runway of Lvliang Airport. The landslide presented 3 steps on the landform, which were divided into 3 blocks, i.e., I, II, and III (Figure 1(c)). The development of the II landslide led to the III landslide deformation. Moreover, the development of I landslide based on the II landslides. The I landslide had 3 sub-blocks, i.e., I-1, I-2, and I-3 [37]. The slip zone inside I-1 and I-2 landslides was revealed by exploratory trench and 

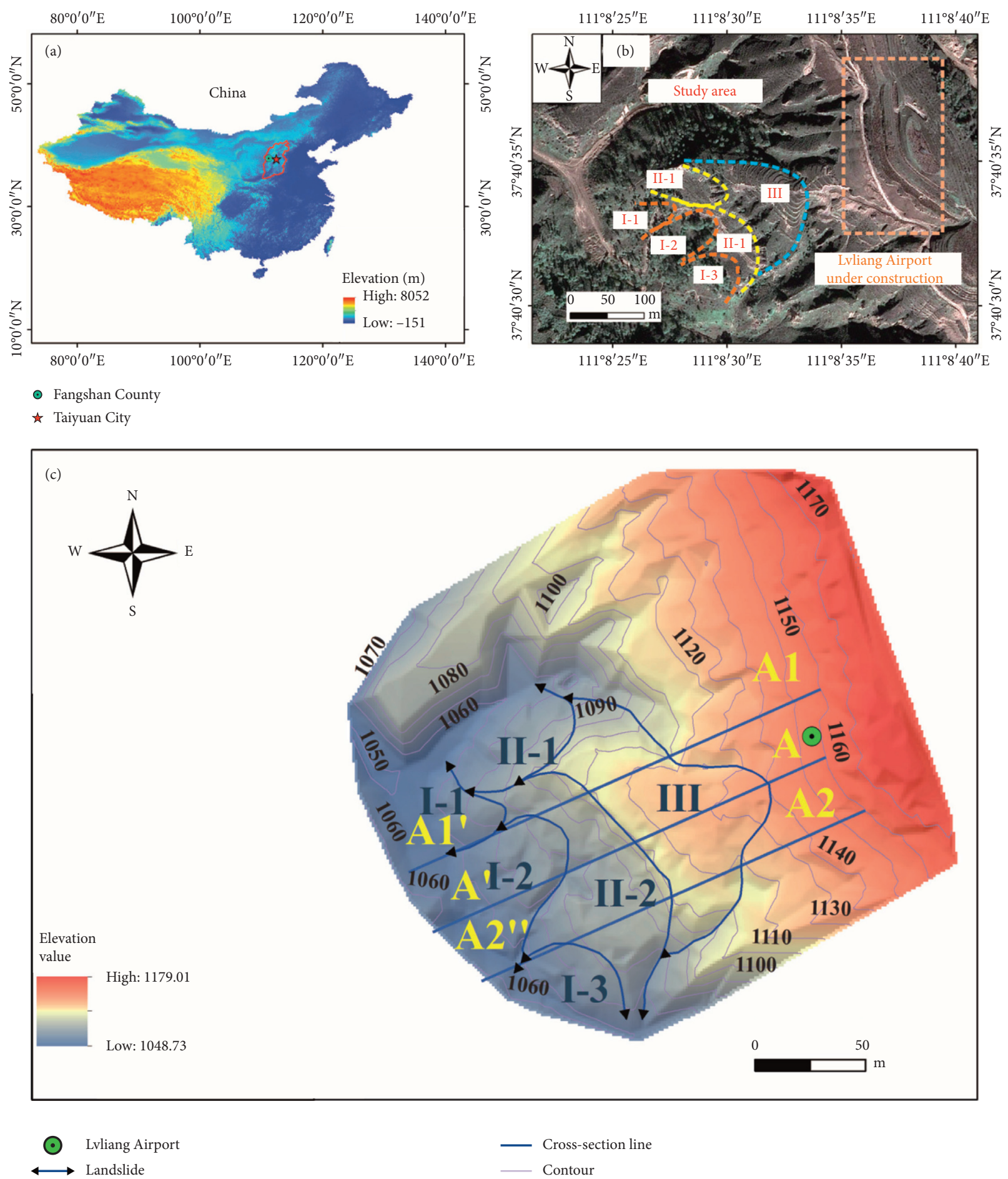

FIgUre 1: The location of Lvliang Airport. (a) Location within China. (b) Spatial relationship between study area and Lvliang Airport. (c) Plan view and location of the landslide.

drilling. It could be concluded preliminarily that I-1 and I-2 landslides were in the ultimate equilibrium stage. The back wall of the I-3 landslide was strewn at a random height of about $5 \mathrm{~m}$ obviously. Large gullies were developed on both sides of the landslide, so it was easy to determine the landslide perimeter. Furthermore, part of the leading edge of the I-3 landslide had collapsed, indicating that the landslide was currently in the fretting stage and was likely to slide under the action of heavy rain or prolonged rainfall. The II landslide consisted of two blocks, i.e., II-1and II-2. There were many well-developed fissures in the back wall of the II1 landslide. During the exploration of the II-2 landslide, part of the leading edge of the landslide had collapsed, indicating the creep of the block. At present, the grade III landslide was 


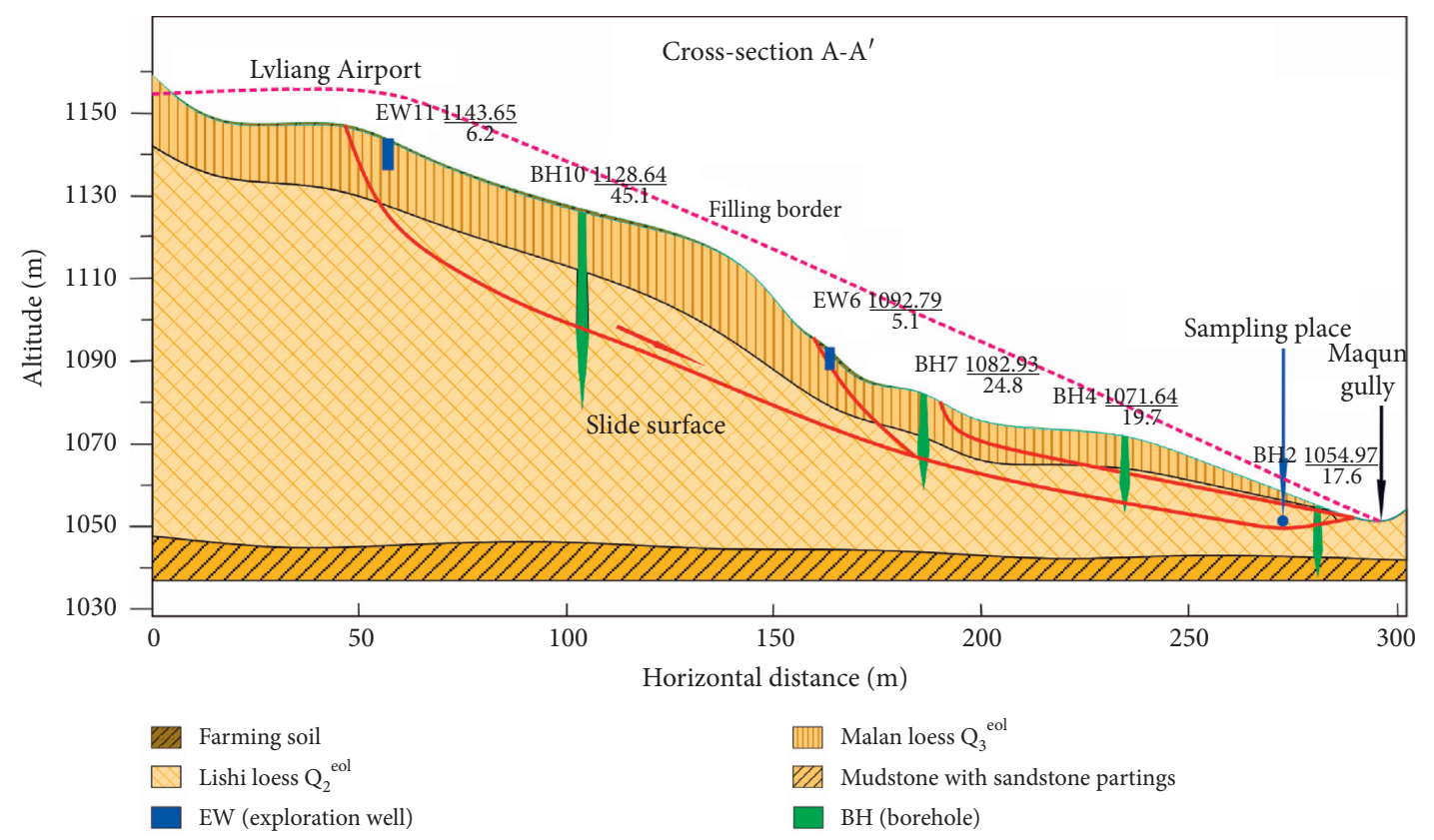

Figure 2: Longitudinal section of the landslide along line A-A' in Figure 1.

basically stable. However, it is easy to cause landslide revival under the action of the earthquake, prolonged rain or rainstorm, and airport construction. According to the characteristics of the slip zone revealed by drilling (Figures 2 and 3), it could be seen that the slip zone of the main landslide was located in the ancient loess soil layer, and the tendency of the sliding surface was basically consistent with the slope direction.

The investigated area has an arid or semiarid climate. The annual precipitation is about $600 \mathrm{~mm}$. About $75 \%$ of the rainfall occurs in the rainy season from June to September, and the interannual variation is great, with a difference of 2 3 times between the years with the highest precipitation and the years with the lowest (Figure 4). Due to the lateral erosion and downward erosion of the flood at the foot of the slope, the surface of the leading edge of the I landslide is constantly raised, leading to the revival of the I landslide, and thus leading to the revival of the II landslide, which is likely to induce the overall sliding. At the same time, fissures are obviously dispersed in the landslide mass and surface water is easy to infiltrate along the fissures, accelerating the resurrection of the landslide, thus threatening the airport construction. In order to reduce the risk of landslide and avoid the recurrence of landslide, effective methods should be taken to treat the landslide.

2.2. Materials and Specimen Preparation. Preliminary exploration wells and boreholes showed that the potential slip zone was basically located in $Q_{2}^{\text {eol }}$ layer of Lishi loess (Figure 2), so the intact $Q_{2}$ loess taken from the slip zone 20 meters deep underground was used in this paper. The loess was cut into a cylindrical specimen (diameter of $39.1 \mathrm{~mm}$ and height of $80 \mathrm{~mm}$ ), with a special cutting apparatus. The upper and lower surfaces of the prepared specimen should be smoothed, the moisture was controlled at $15.2 \pm 1 \%$, and the difference in the dry density was not more than $0.02 \mathrm{~g} / \mathrm{cm}^{3}$. According to the particle distribution curve Figure 5, the loess consisted mainly of silt (about 95\%) with some clay (about 14\%), and the mean particle diameter was $0.02 \mathrm{~mm}$. After the preparation, the initial matric suction of the undisturbed were $180 \mathrm{kPa}$ determined by the axistranslation technique. The main physical parameters of the loess are illustrated in Table 1.

The filling material is a mixture of fly ash and nano- $\mathrm{SiO}_{2}$. The fly ash (Ca) mainly consists of $\mathrm{SiO}_{2}$ and $\mathrm{Al}_{2} \mathrm{SO}_{3}$ (Figure 6), which was taken from Datang Baqiao Thermal Power Plant in Xi'an. The specific composition is shown in Figure 1. The nano- $\mathrm{SiO}_{2}$ with a purity of $99.5 \%$ and a particle size of $50 \pm 5 \mathrm{~nm}$ was purchased from Shanghai Macklin Biochemical Technology Co., Ltd., more details are shown in Table 2.

In this paper, three proportions of fly ash $(5 \%, 10 \%$, and $15 \%$ of the dry weight of loess) and two ratios of nano- $\mathrm{SiO}_{2}$ (3\% and $5 \%$ of the dry weight of fly ash) were mixed with loess, respectively, and prepared for tests with the orthogonal design method. Before the test, the loess taken from the slip zone were dried, crushed, and sieved by $0.25 \mathrm{~mm}$ and mixed evenly with fly ash and nano- $\mathrm{SiO}_{2}$. Then, add water to make its moisture content reach the same target value as that of the undisturbed $(\omega=15.2 \%)$. After that place the mixture into a plastic bag in a humid room for two days. The remoulded with a diameter of $39.1 \mathrm{~mm}$ and a height of $80 \mathrm{~mm}$ were prepared by using a metal mold and were placed in a standard curing box for 7 days.

2.3. Apparatus. The saturated-unsaturated stress path triaxial apparatus manufactured by GDS Company was selected. The instrument consists of three parts: controller (including 2 hydraulic controllers and 1 pneumatic 

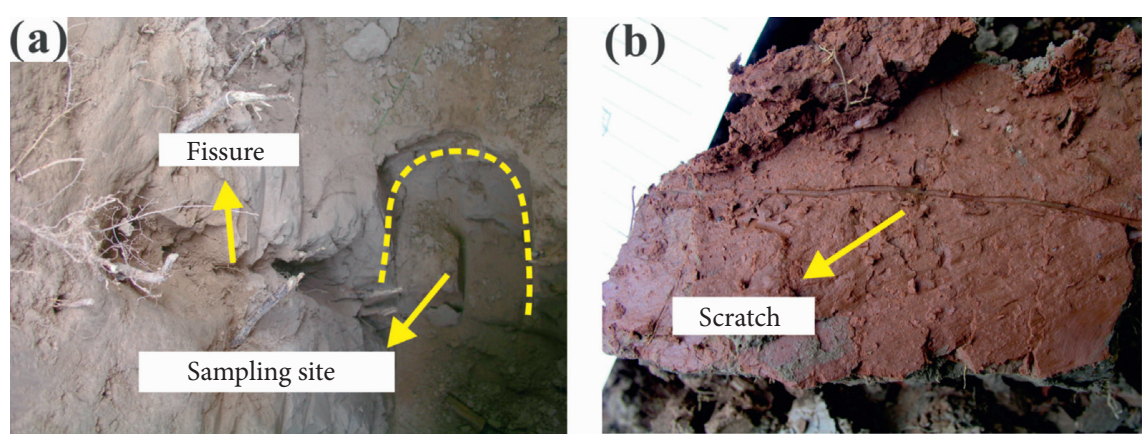

Figure 3: Photos showing the sliding site from different locations. (a) The loess sample from the slip zone. (b) Scratch on the slip zone.

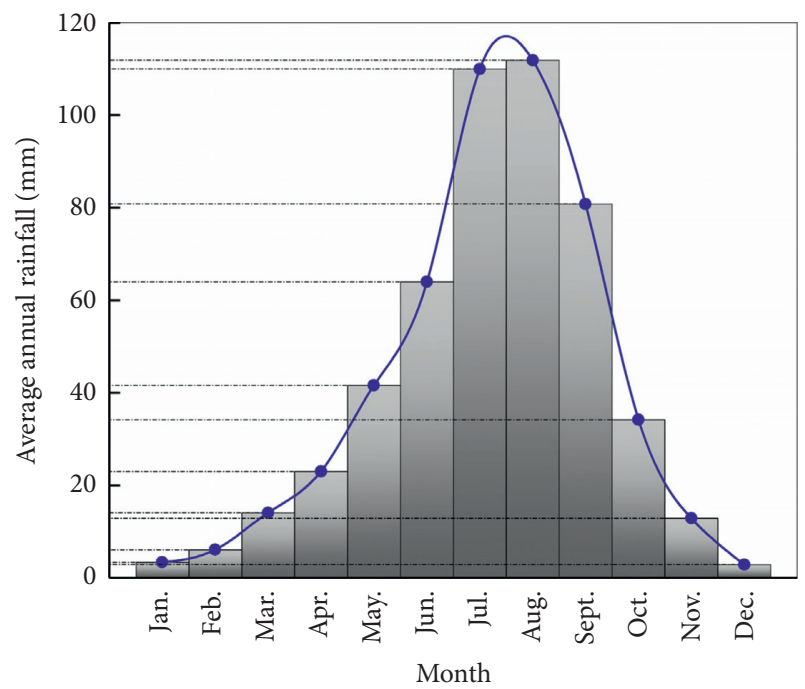

FIGURE 4: The monthly distribution of the average annual rainfall applied in Lvliang Airport.

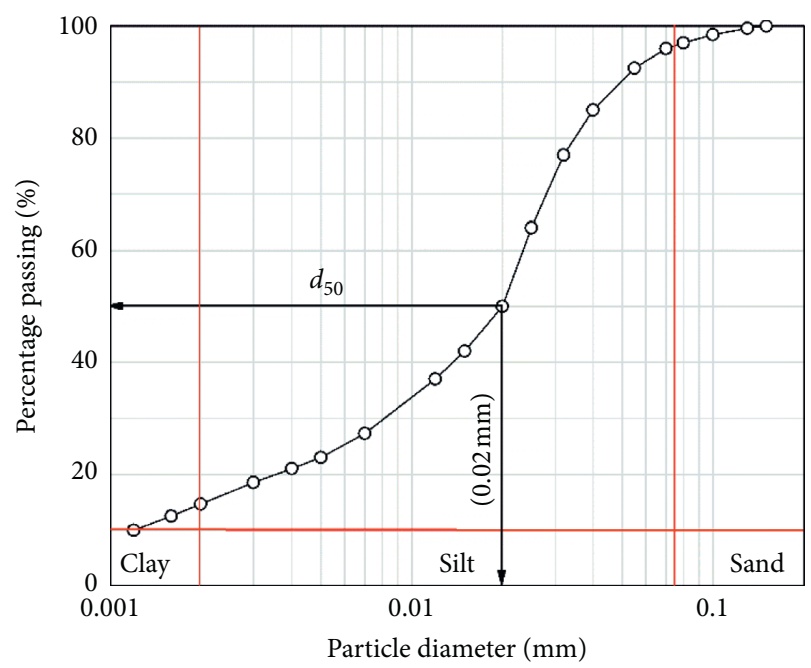

Figure 5: Particle-size distribution of Lishi loess.

controller), pressure chamber, and data acquisition system (including sensor, data acquisition board, and computer). The computer control and analysis system can collect and process data live.
To carry out wetting tests, a humidifying device was added to the system. This device has a twin-tube with pressure transducer, which connected to the top cap. And a valve was used to control the water injection amount. Varying water level in the twin-tube was measured by a transducer (range $6 \mathrm{kPa}$ and precision $0.01 \mathrm{kPa}$ ) and then converted to change in water volume (range $20 \mathrm{~cm}^{3}$ and precision $0.01 \mathrm{~cm}^{3}$ ).

The internal structure of the instrument is shown in Figure 7(c). Before the tests, water was injected into the inner triaxial cell $3 \mathrm{~cm}$ away from the top. The air pressure of outer triaxial cell was connected with the inner cell water, which were used as the confining pressure. The axial pressure was applied and measured by the controller connected to the base of instrument (range $1 \mathrm{kPa}$ and precision $0.001 \mathrm{~cm}^{3}$ ). The pressure cell base consists of three parts. The outer is an annular perforated plate linked with air pressure loading device, applying and measuring pore air pressure $u_{a}$. The middle is an aluminum alloy partition wall, and the inner is a porous plate with a high air intake value of $5 \mathrm{bar}$, controlling and measuring matric suction. The porous plate whose lower part is connected with the back pressure controller and the pore water pressure transducer can be used for the porous plate flushing and back pressure and pore water pressure measurement. This equipment can meet the needs of the tests in this paper.

2.4. Testing Procedures. In this paper, to investigate the reinforcement mechanism of the filling material on the loess taken from the slip zone, laboratory tests were conducted, including conventional triaxial shear tests, under constant matric suction (for the undisturbed and the remolded) and wetting tests under constant deviator stress (for the remoulded). The main parameters are shown in Tables 3 and 4 , respectively. In addition, under the axisymmetric condition $\left(\sigma_{2}=\sigma_{3}\right)$, the deviator stress is defined as $q=\sigma_{1}-\sigma_{3}$, $p=\left(\sigma_{1}+2 \sigma_{3}\right) / 3$ is the mean stress, $p^{\prime}=p-u_{a}$ is the net mean stress, and the matrix suction is defined as $s=u_{a}-u_{w}$, where $u_{a}$ and $u_{w}$ are pore air pressure and pore water pressure, respectively.

The first group of tests was conventional drainage triaxial shear test (ST1) under constant matric suction. Four net confining pressures $(50,100,200$, and $400 \mathrm{kPa})$ were selected for the experiment, and more parameters are shown in Table 3. During the experiment, the matric 
TABLe 1: Physical parameters of undisturbed loess.

\begin{tabular}{lccccccccc}
\hline Sample & $w(\%)$ & $G_{s}$ & $\rho\left(\mathrm{g} / \mathrm{cm}^{3}\right)$ & $\rho_{d}\left(\mathrm{~g} / \mathrm{cm}^{3}\right)$ & $e$ & $w_{L}(\%)$ & $w_{p}(\%)$ & $I_{p}(\%)$ & Classification \\
\hline Lishi loess & 15.2 & 2.70 & 1.67 & 1.45 & 0.86 & 27.4 & 15.1 & 12.3 & Silty clay \\
\hline
\end{tabular}

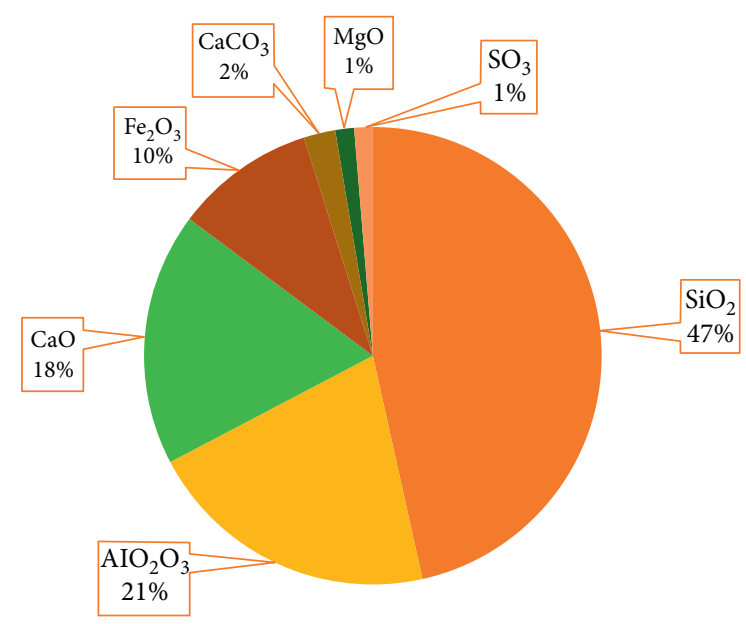

Figure 6: Chemical composition of fly ash.

TABLE 2: Specification of nanosilica.

\begin{tabular}{|c|c|c|c|}
\hline Item no. & S817567 & Purity & $99.5(\%)$ \\
\hline Particle size & $50 \pm 5 \mathrm{~nm}$ & Melting point & $1610^{\circ} \mathrm{C}$ (lit.) \\
\hline CAS no. & 60676-86-0 & Density & $\begin{array}{c}2.6 \mathrm{~g} / \mathrm{mL} \text { at } 25^{\circ} \mathrm{C} \\
\text { (lit.) }\end{array}$ \\
\hline MDL no. & MFCD00011232 & $\begin{array}{l}\text { Refractive } \\
\text { index }\end{array}$ & $n 20 / D 1.544$ (lit.) \\
\hline EINECS no. & $262-373-8$ & $\begin{array}{l}\text { Storage } \\
\text { condition }\end{array}$ & $\begin{array}{c}\text { Indoor } \\
\text { temperature }\end{array}$ \\
\hline
\end{tabular}

suction to be maintained was $180 \mathrm{kPa}$, which was consistent with the value of the loess measured by the axis-translation technique in the natural state, so as to simulate the stress state of the natural loess. The purpose of the tests is to study the deformation properties of undisturbed loess during the shear process and get the cohesion $(C)$ and internal friction angle $(\Phi)$ of loess. At the beginning of the test, the pore air pressure $(180 \mathrm{kPa})$ and confining pressure $(5 \mathrm{kPa})$ were applied to the specimen, and the drainage valve was opened to balance the matric suction. The completion of suction balance is marked by the stable drainage volume (variable quantity less than $0.01 \mathrm{~cm}^{3} / 2 \mathrm{~h}$ ). Then, in the case where the confining pressures increased to $50,100,200$, and $400 \mathrm{kPa}$, respectively, consolidation under constant matric suction was conducted. The sign of consolidation stability is that the increment of overall volume change and drainage volume within two hours less than $0.01 \mathrm{~cm}^{3}$. After that the shear stage started and the shear rate was controlled at $0.004 \mathrm{~mm} / \mathrm{min}$. During the test, the variations of axial strain, overall volume change, and pore water pressure over time were recorded by GDSLAB software, assuming that when the axial strain reaches $15 \%$, the loess reaches failure.
The second group of tests are conventional drainage triaxial shear tests (ST2) on remolded loess containing stabilizers of different proportions, in order to investigate the deformation characteristics of remoulded loess and to obtain cohesion $(C)$ and internal friction angle $(\Phi)$, so as to compare the strength increment of loess before and after grouting. During the experiment, the specimens were subjected to matric suction balance, consolidation, and shear under constant suction in turn. The test was finished when the axial strain reached $15 \%$. It should be noted that samples containing materials of different ratios should be tested under the matric suction, which have been measured by the axis-translation technique in advance. Table 3 shows shear strength parameters $(C$ and $\Phi)$ of loess stabilized with 5 kinds of ratios of materials. Finally, by comparing the reinforcement effects of the filling materials with different ratios, the optimal ratio was selected for the third group of tests.

The third group of experiments is wetting tests (WT) under constant deviator stress for the remolded after grouting. These tests aimed to simulate the stress path of the loess unit taken from the slip zone after grouting under the effect of rainfall wetting, so as to investigate the stability of the slope after wetting. During these tests, the stress path of the remolded were the same as that of the second test group, and the deviator stress corresponding to three kinds of stress levels $R_{s}$ were loaded, respectively. Then, the precalculated water was gradually added under the constant deviator stress and constant confining pressure. Herein, the stress level $R_{s}$ is defined as the ratio of the current deviator stress $q$ and the deviator stress when failure $q_{f}$. In these tests, three stress levels $(0.25,0.5$, and 0.75$)$ and four net confining pressures $(50,100,200$, and $400 \mathrm{kPa})$ were selected, respectively. The results are shown in Table 4 . It is noted that, in order to avoid the partial erosion damage of the specimens by water, the wetting criterion was introduced, i.e., the wetting series was at least six or the moisture increment was not more than $2 \%$ at each stage. The criteria for the sample to reach a stable state was proposed, when the overall volume change increment was less than $0.01 \mathrm{~cm}^{3} / 2 \mathrm{~h}$, the matric suction increment was less than $1 \mathrm{kPa} / 2 \mathrm{~h}$ and the axial strain increment was less than $0.005 \mathrm{~mm} / \mathrm{h}$.

\section{Results}

3.1. ST Results. Under $\sigma_{3}-u_{a}=50$ and $200 \mathrm{kPa}$, the relationship between deviator stress and axial strain of the undisturbed and the remoulded with materials of six different proportions are illustrated in Figure 8. There are no peaks in the $q-\varepsilon_{1}$ curves, meaning a lower brittleness of the sample and achieving the critical state at larger strain. It can be clearly found that the deviator stress at failure increases with the material content, which shows that the stabilizer 


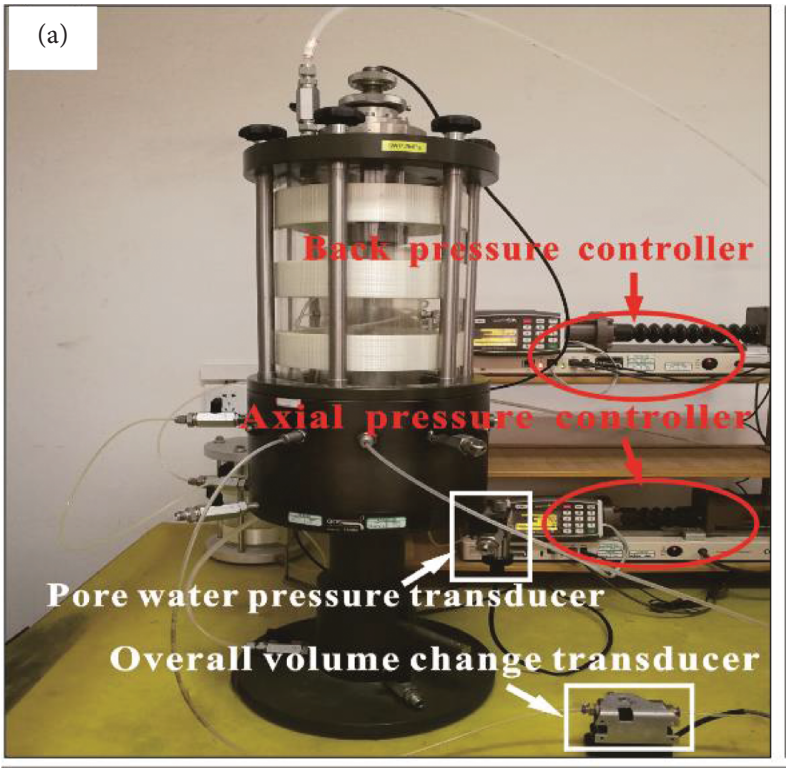

(b)

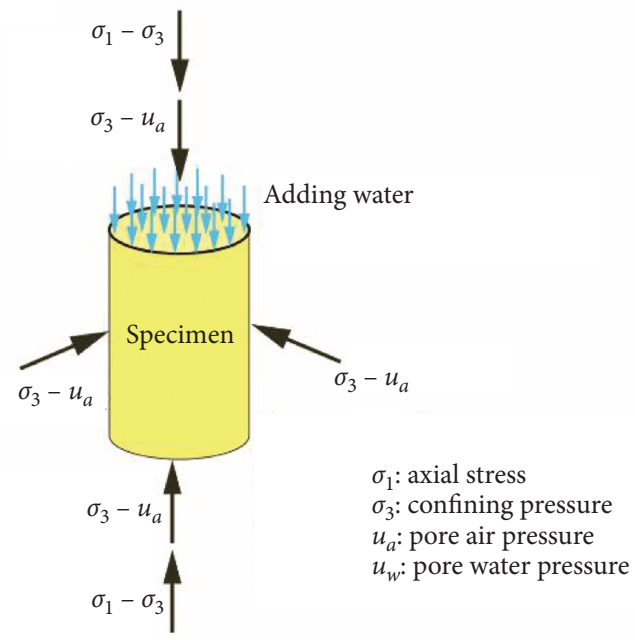

(c)

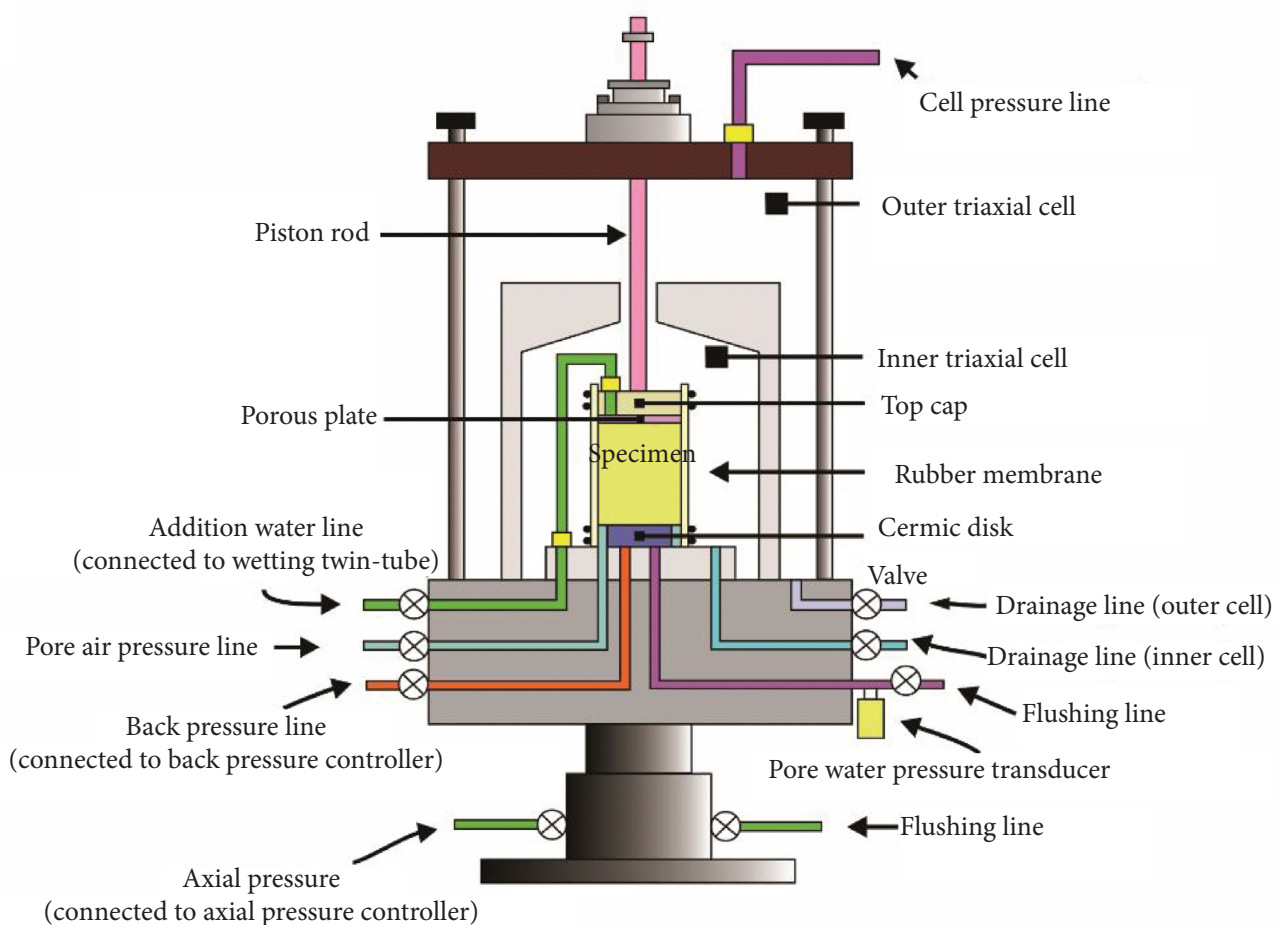

FIGURE 7: GDS triaxial test instrument (a) overview; (b) specimen in the triaxial cell; (c) schematic diagram of suction-monitored triaxial apparatus.

can improve the strength of the loess. However, the increment of strength gradually decreases with the uphill of material, indicating that the improvement is limited, such as B1, B2, and B3 in Figure 8. Meanwhile, for specimens with the same content of fly ash, the increase of nano- $\mathrm{SiO}_{2}$ significantly enhances the strength of the soil, for instance, A2 and B2 in Figure 8.

To further analyze the reinforcement effect of grouting materials on loess, Figure 9 shows the curves of the deviator stress-axial strain and the volumetric strain-axial strain under different net confining pressures about the undisturbed (a) and the remoulded (b and c). All $q-\varepsilon_{1}$ curves under different net confining pressures show a trend from steep to slow, which is mainly because the structural damage at the initial stage of loading is the main factor affecting the soil structure. And the structural parameters [38,39] reduce rapidly with the development of strain. When the strain gets large, the soil structure gradually heals and forms a new 
TABLE 3: Testing results of the ST tests.

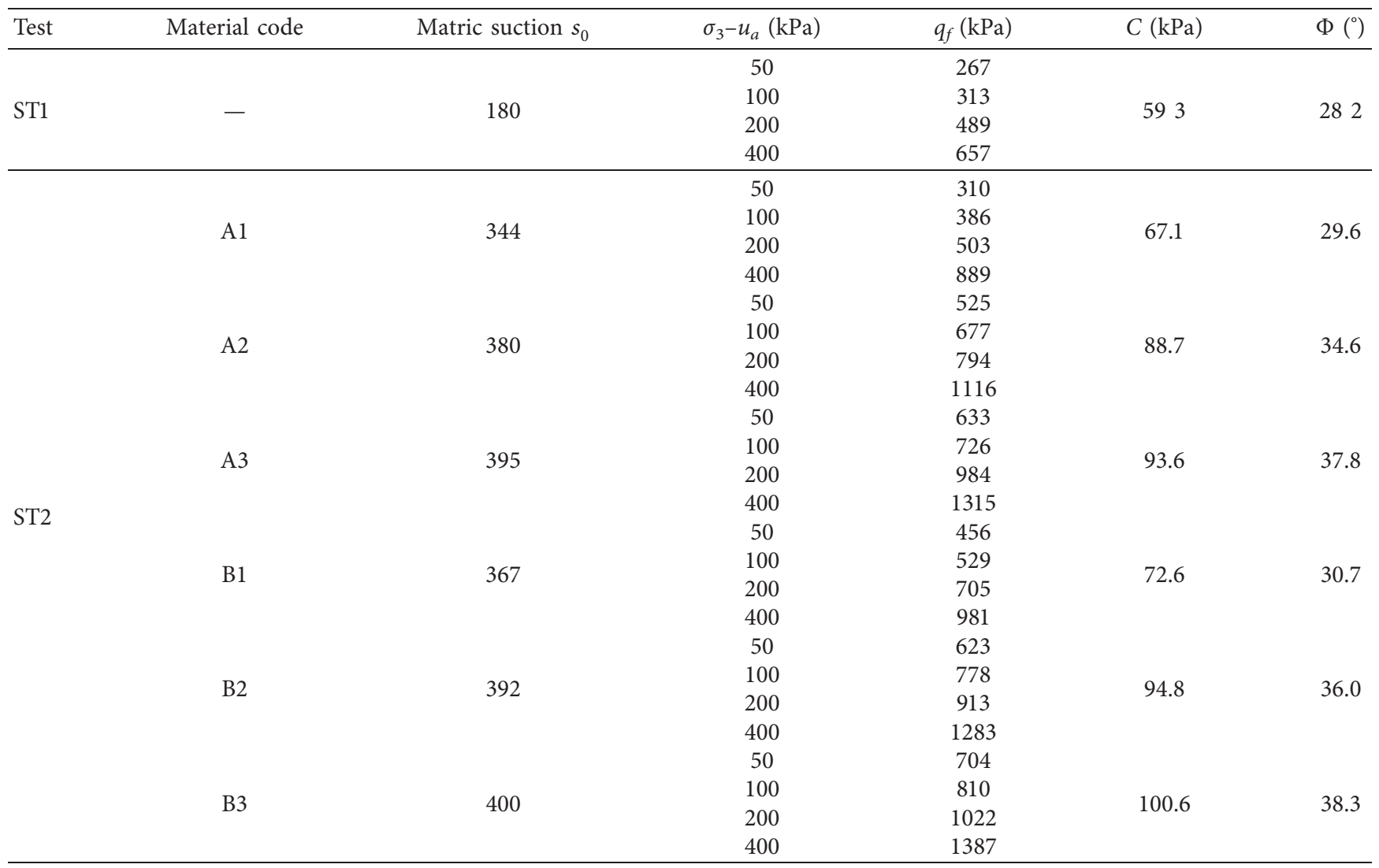

$q_{f}$ is deviator stress when failure, $C$ is cohesion, $\Phi$ is internal friction angle, $\mathrm{A}$ is materials containing $3 \%$ nanosilica, and $\mathrm{B}$ is materials containing $5 \%$ nanosilica.

TABLE 4: Testing results of the WT tests.

\begin{tabular}{|c|c|c|c|c|c|c|c|}
\hline \multirow{2}{*}{ Test } & \multirow{2}{*}{ Material content (\%) } & \multirow{2}{*}{$s_{0}(\mathrm{kPa})$} & \multirow{2}{*}{$\sigma_{3}-u_{a}(\mathrm{kPa})$} & \multirow{2}{*}{$R_{s}$} & \multirow{2}{*}{ After shear but before wetting $S_{r}(\%)$} & \multicolumn{2}{|c|}{ After wetting } \\
\hline & & & & & & $s_{f}(\mathrm{kPa})$ & $S_{r f}(\%)$ \\
\hline \multirow{12}{*}{ WT1 } & \multirow{12}{*}{10} & \multirow{12}{*}{380} & \multirow{3}{*}{50} & 0.25 & 44.2 & - & 96.3 \\
\hline & & & & 0.5 & 46.7 & 15 & 95.2 \\
\hline & & & & 0.75 & 44.5 & 88 & 75 \\
\hline & & & \multirow{4}{*}{100} & 0.25 & 48.6 & - & 96.6 \\
\hline & & & & 0.5 & 47.3 & 107 & 74 \\
\hline & & & & 0.75 & 50.3 & 158 & 68 \\
\hline & & & & 0.25 & 49.6 & - & 98.1 \\
\hline & & & \multirow[t]{3}{*}{200} & 0.5 & 43.1 & - & 97.3 \\
\hline & & & & 0.75 & 48.3 & 75 & 82 \\
\hline & & & & 0.25 & 40.9 & - & 95.8 \\
\hline & & & \multirow[t]{2}{*}{400} & 0.5 & 47.7 & - & 97.5 \\
\hline & & & & 0.75 & 50.8 & 84 & 79 \\
\hline \multirow{12}{*}{ WT2 } & \multirow{12}{*}{15} & \multirow{12}{*}{392} & \multirow{3}{*}{50} & 0.25 & 52.6 & - & 98.4 \\
\hline & & & & 0.5 & 48.6 & - & 96.2 \\
\hline & & & & 0.75 & 48.3 & 12 & 95.5 \\
\hline & & & \multirow{4}{*}{100} & 0.25 & 44.3 & - & 97.3 \\
\hline & & & & 0.5 & 47.6 & 17 & 94.3 \\
\hline & & & & 0.75 & 44.9 & 77 & 82 \\
\hline & & & & 0.25 & 48.8 & - & 98.1 \\
\hline & & & \multirow[t]{3}{*}{200} & 0.5 & 49.7 & - & 97.9 \\
\hline & & & & 0.75 & 45.8 & 95 & 76 \\
\hline & & & & 0.25 & 53.2 & - & 97.3 \\
\hline & & & \multirow[t]{2}{*}{400} & 0.5 & 49.4 & - & 96.7 \\
\hline & & & & 0.75 & 50.5 & - & 95.9 \\
\hline
\end{tabular}


TABLE 4: Continued.

\begin{tabular}{|c|c|c|c|c|c|c|c|}
\hline \multirow{2}{*}{ Test } & \multirow{2}{*}{ Material content (\%) } & \multirow{2}{*}{$s_{0}(\mathrm{kPa})$} & \multirow{2}{*}{$\sigma_{3}-u_{a}(\mathrm{kPa})$} & \multirow{2}{*}{$R_{s}$} & \multirow{2}{*}{ After shear but before wetting $S_{r}(\%)$} & \multicolumn{2}{|c|}{ After wetting } \\
\hline & & & & & & $s_{f}(\mathrm{kPa})$ & $S_{r f}(\%)$ \\
\hline \multirow{12}{*}{ WT3 } & \multirow{12}{*}{20} & \multirow{12}{*}{395} & \multirow{3}{*}{50} & 0.25 & 48.5 & - & 95.4 \\
\hline & & & & 0.5 & 47.9 & - & 95.9 \\
\hline & & & & 0.75 & 50.3 & - & 97.5 \\
\hline & & & \multirow{4}{*}{100} & 0.25 & 45.9 & - & 96.6 \\
\hline & & & & 0.5 & 43.2 & - & 98.7 \\
\hline & & & & 0.75 & 44.8 & - & 97.3 \\
\hline & & & & 0.25 & 50.3 & - & 96.1 \\
\hline & & & \multirow[t]{3}{*}{200} & 0.5 & 48.5 & - & 97.2 \\
\hline & & & & 0.75 & 48.1 & - & 98.9 \\
\hline & & & & 0.25 & 47.9 & - & 96.4 \\
\hline & & & \multirow[t]{2}{*}{400} & 0.5 & 49.1 & - & 95.8 \\
\hline & & & & 0.75 & 46.7 & - & 95.9 \\
\hline
\end{tabular}

$S_{0}$ is initial matric suction, $R_{s}$ is stress level, $s_{f}$ is matric suction when failure, and $S_{r f}$ is degree of saturation when failure-no failure.

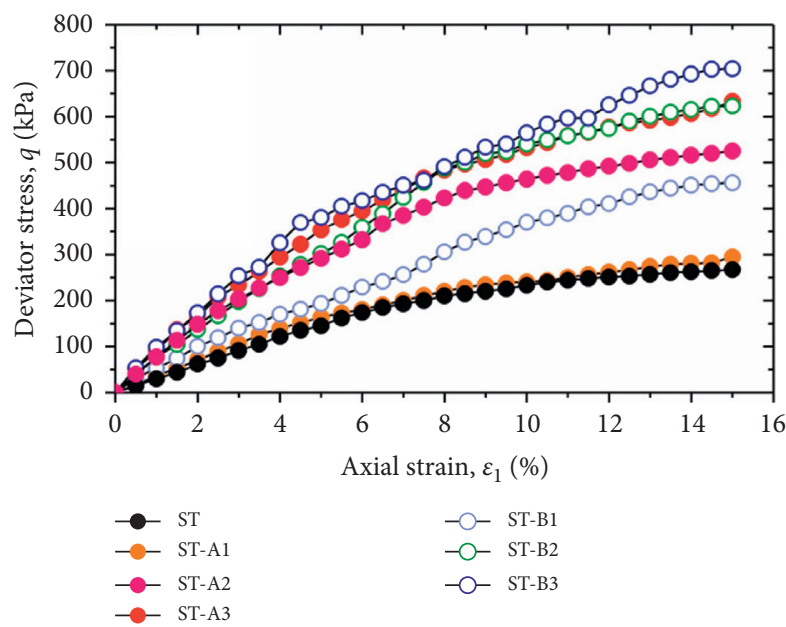

(a)

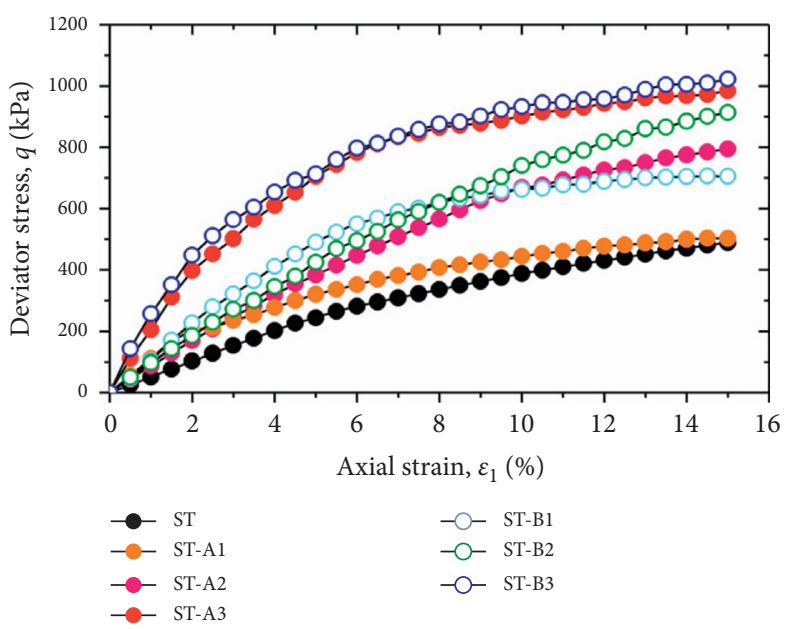

(b)

FIGURE 8: Effects of filling material content on the stress-axial strain curves for various controlled net confining pressures: (a) $\sigma_{3}-u_{a}=50 \mathrm{kPa}$ and (b) $\sigma_{3}-u_{a}=200 \mathrm{kPa}$.

secondary structure, which inhibits the structural damage factors from further weakening the soil structure [40]. At the same time, the tendency that the volumetric strain diminishes with the rise of net confining pressure also suggests that an increase in net confining pressure results in a rise in deformation resistance of the undisturbed or the remoulded, which further indicates that the uphill of net confining pressure is more conducive to the compaction of the undisturbed and the formation of secondary structure, for example, Figures 9(a)-9(c).

What is noteworthy is that, for the curve $q-\varepsilon_{1}$, when the axial strain of the undisturbed reaches $4 \%-5 \%$, there occurs an obvious turning point. After that the slope quickly changes from big to small, indicating that the initial structure of the sample was obviously damaged at this point. However, for the remoulded, the axial strain is larger than the undisturbed when the initial structure is obviously broken, illustrating that the deviator stress required for the failure is larger. And it reflects that the stabilizer effectively improved the strength of the loess. Furthermore, the initial structural failure point of the remoulded B2 is about $9 \%$ (Figure 9(c)), while that of the remoulded A2 is about $10 \%$ (Figure 9(b)), implying that the sample B2 (containing 5\% nano- $\mathrm{SiO}_{2}$ ) has better improvement effect than sample A2 (containing 3\% nano- $\mathrm{SiO}_{2}$ ). That is to say, the increase of nano- $\mathrm{SiO}_{2}$ is conducive to the improvement of loess strength, which is consistent with what Sarli et al. found in their study [26].

The over volume change induced by shearing is observed in Figures 9(a)-9(c). The volumetric strain enlarges with increasing axial strain, while the slope of the curve decreases. Through comparison, it can be found that the volumetric strain of the remoulded is smaller than the undisturbed, when reaching the same axial strain, indicating that the ability of loess to resist deformation is enhanced by the stabilizer. Moreover, the antideformation capacity would improve with the uphill of nano- $\mathrm{SiO}_{2}$ consumption (Figures 9(c)-9(b)). This is mainly because the soil behaviour 

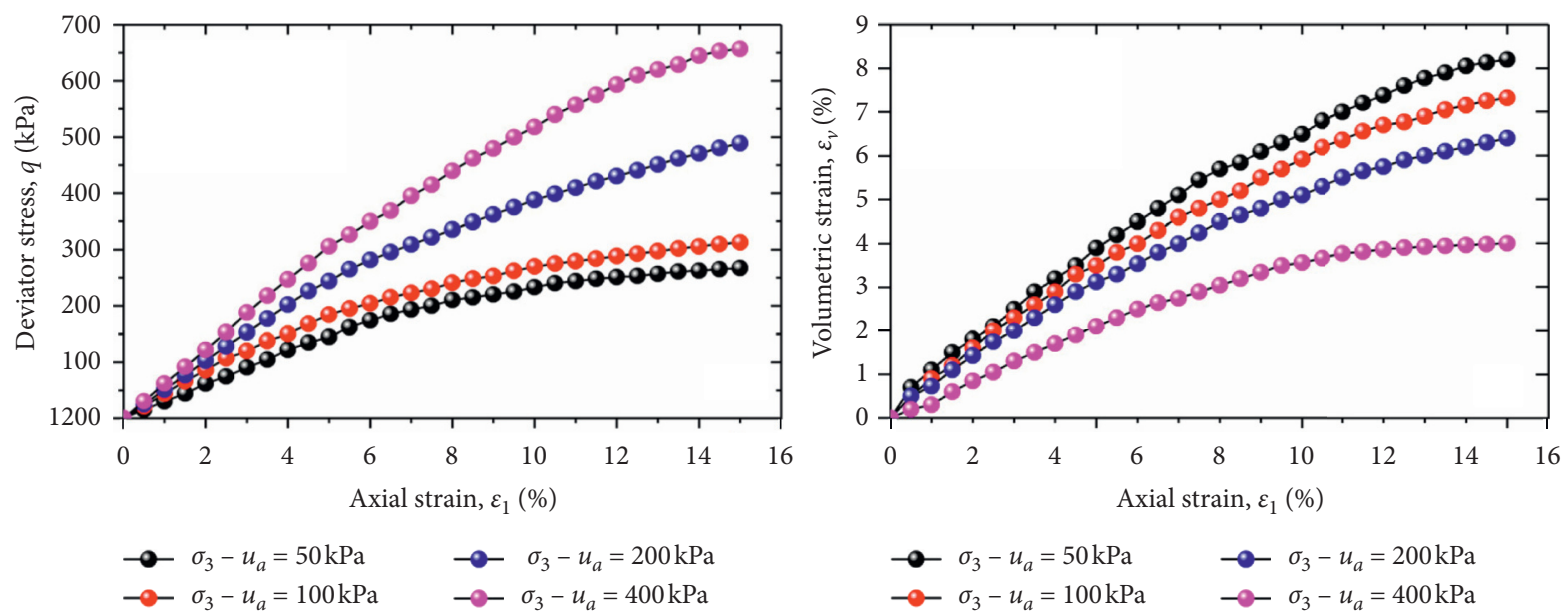

(a)
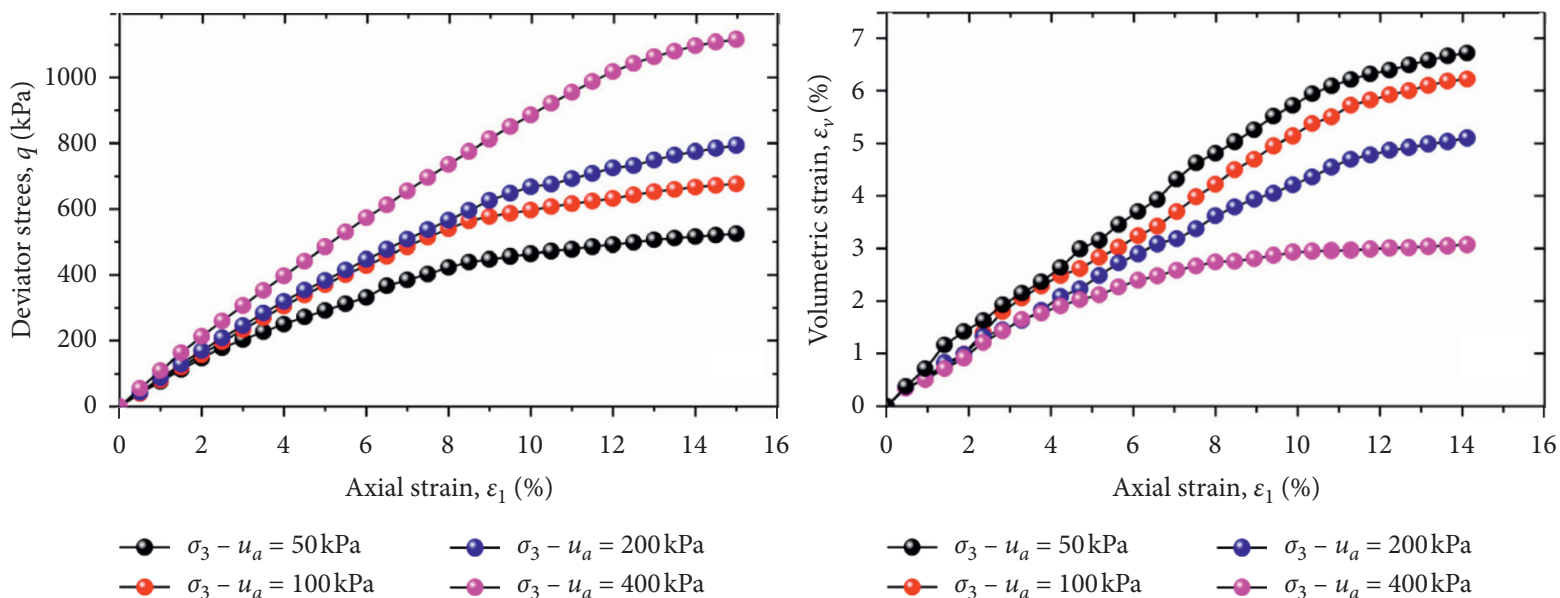

(b)
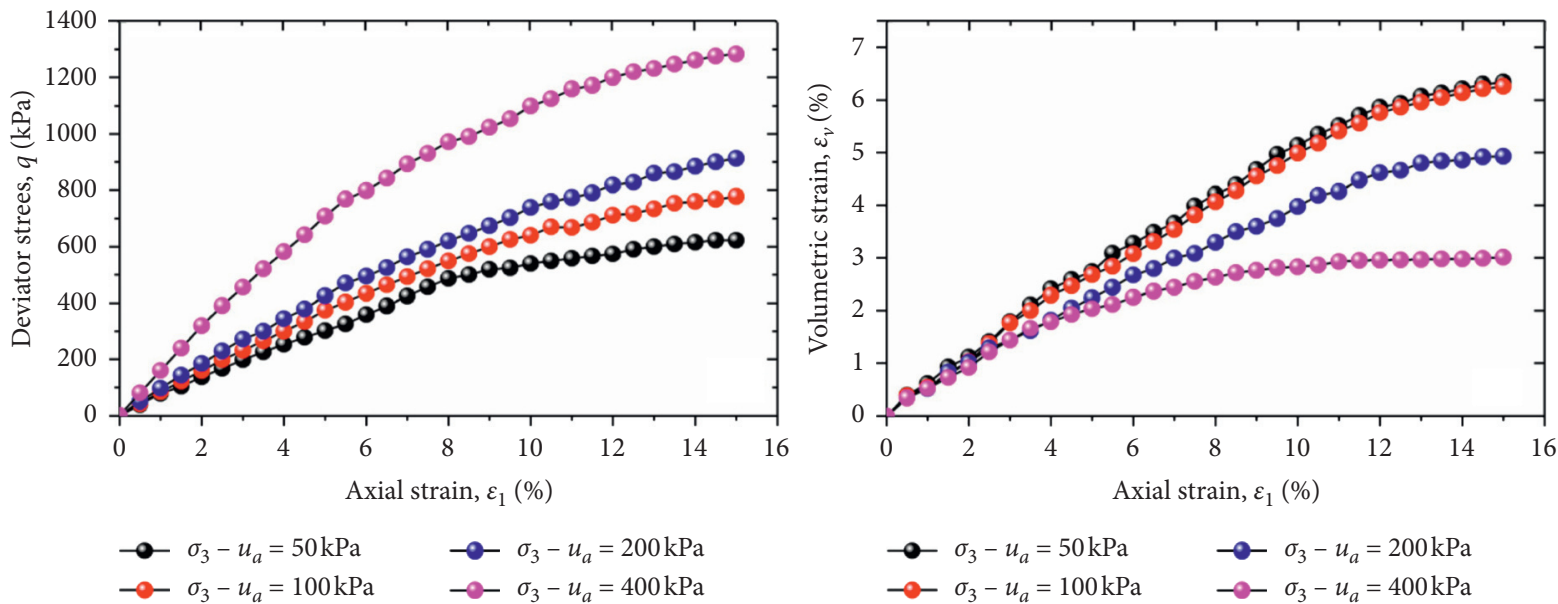

(c)

FIGURE 9: Effects of filling material content on the stress-axial strain and volumetric strain-axial strain curves for various controlled net confining pressures: (a) undisturbed sample, (b) grouting sample (3\% nanosilica), and (c) grouting sample (5\% nanosilica). 
depends, to a large extent, on the soil constituents and structure [41], and the nano- $\mathrm{SiO}_{2}$ could fill the pores inside the solidified loess aggregates, forming aggregates with tighter contact and larger size [42]. In addition, due to the strong alkalinity of the loess, siliceous cementing materials can be created after the reaction with silica, which significantly reduces the porosity and improves the bonding in the loess, and thus building up the strength and stiffness of the loess [43].

The critical state of the undisturbed and the remoulded from ST are shown on a $q-p$ plane in Figure 10. For the undisturbed and the remoulded, the critical state line (CSL) is well fitted to a straight line on the $q$ - $p$ plane, meaning that the shear strength of the soil can be described by the Mohr-Coulomb strength criterion. Moreover, the cohesion and internal friction angle of the loess sample can be obtained by the slope $(M)$ and intercept $(H)$ of the fitted line, which are determined by formulas, i.e., $c=(3-\sin \Phi)$ $\mathrm{H} /(6 \cos \Phi)$ and $\Phi=\sin ^{-1}[3 M /(6+M)]$. The cohesion and internal friction angle are shown in Table 3.

In order to facilitate the comparison of the reinforcement effect, the increment percentage of the cohesion and internal friction angle of the remoulded relative to the undisturbed were plotted on a three-dimensional diagram (Figure 11). The data points (marked with sphere) stand for comprehensive reflection of $C$ and $\Phi$ increment, and the other (marked with star) represent the projection of spherical data points on each two-dimensional plane. It is noted that all data points are positive, suggesting that the cohesion and internal friction angle of the remoulded are significantly improved, compared with the undisturbed. Additionally, samples containing $5 \%$ nano- $\mathrm{SiO}_{2}$ is obviously better than that containing $3 \%$ nano- $\mathrm{SiO}_{2}$, in terms of the improvement of the cohesion and the internal friction angle, which proves that the existence of the nano- $\mathrm{SiO}_{2}$ greatly reinforces the shear strength of the loess, and within a certain range, this kind of improvement is proportional to the amount of nano- $\mathrm{SiO}_{2}$.

On the whole, the cohesion and the internal friction angle increase with the stabilizer content, but the trend that the line gradually becomes slower from steepness indicates that the improvement effect is limited. Namely, there must be an appropriate threshold value (around 15\%). When the material content exceeds the threshold, the increasing rate of cohesion and internal friction angle caused by the stabilizer will slow down, suggesting that more cost input leads to an inconspicuous increase in benefits. In order to find the threshold (the optimal solution), the mathematical dichotomy was introduced in this paper. Through ST tests at three discrete points (stabilizer content of 5\%, 15\%, and 25\%, respectively), the turning point (15\%) was found when the test curves significantly changed from steep to gentle. Therefore, it could be predicted that the threshold for the experiment must be near the turning point. Consequently, taking $15 \%$ as the benchmark, the upper and lower two intervals $[5,15,25]$ were divided in half to selected discrete points (10\% and $20 \%)$, respectively. Then, the interval of the threshold was further narrowed from $[5,10,20,25]$. On this basis, three kinds of ratios of the stabilizer were selected for
WT test, accounting for $10 \%, 15 \%$, and $20 \%$ of the dry density of loess, respectively, among which the content of nano- $\mathrm{SiO}_{2}$ is $5 \%$.

3.2. WT Results. Wetting Tests (WT2) were conducted on the samples with $15 \%$ stabilizer under three stress level values $(0.25$, 0.5 , and 0.75 ). In order to simulate the wetting process of the slope filled with slurry of different ratios under the same stress state, the samples with the stabilizer ratio of $10 \%$ and $20 \%$, respectively, were loaded under the same confining pressure and deviator stress for wetting test (WT1 and WT3). Under four kinds of net confining pressures $(50,100,200$, and $400 \mathrm{kPa}$ ), the variations of deviator stress with axial strain of the remoulded are presented in Figure 12, assuming that all specimens reach a critical state when the axial strain reach 15\% (marked by star). It was clearly found that all of the specimens did not fail at a low stress level, which was consistent with the findings of Wang et al. [2]. However, at a high stress level, the specimens with $10 \%$ stabilizer all failed under the four confining pressures. In contrast, the specimens with the stabilizer ratio of $20 \%$ did not fail. This shows that, with $20 \%$ slurry being injected into the fissures, the slope can still hold steady under the effect of rainfall wetting.

To further study the relationship between filler and slope stability under rainfall wetting, the WT results under the deviator stress corresponding to the high stress level (0.75) were plotted on the $q-p^{\prime}$ plane (Figure 13). A formula was chosen, i.e., $p^{\prime}=p+S_{r} s$ [44], where $p^{\prime}$ is effective mean stress. The data points (marked with hollow circles) represent the initial stress level of the samples with different ratios of the stabilizer $(10 \%, 15 \%$, and $20 \%)$ before wetting. And the other (marked with solid circles) stands for the stress level after wetting (no damage has occurred), while the solid stars represent the failure induced by wetting. It is noted that, for the samples with the same stabilizer content, the data points associated with failure appear to be on a straight line (CSL). Moreover, the CSL of samples with 15\% stabilizer is above that of the sample with $10 \%$. This indicates that the injection of more slurry into the slope fissures will make it less prone to failure induced by rainfall wetting, as a result, achieving the purpose of improving the stability of the slope. Therefore, through the wetting test (WT) under constant deviator stress, the range of material content threshold was further narrowed to $15 \%-20 \%$.

3.3. Field Test Results. To further examine the effect of new grouting material, the grouting reinforcement experiment of loess and fissures in the potential slip zone of the old landslide in Lvliang Airport was carried out. The grouting pressure was determined, the grouting parameters and the irrigability of the materials were discussed and analyzed. At the same time, according to the actual engineering geological conditions of the test area and the surrounding environment of the test site, the grouting site adopts the combination of the analysis method, inspection hole method, and excavation sampling method to test and analyze the shrinkage, compactness, filling degree, and bonding degree of the material after 28 days. The results are analyzed, as shown in Table 5. 


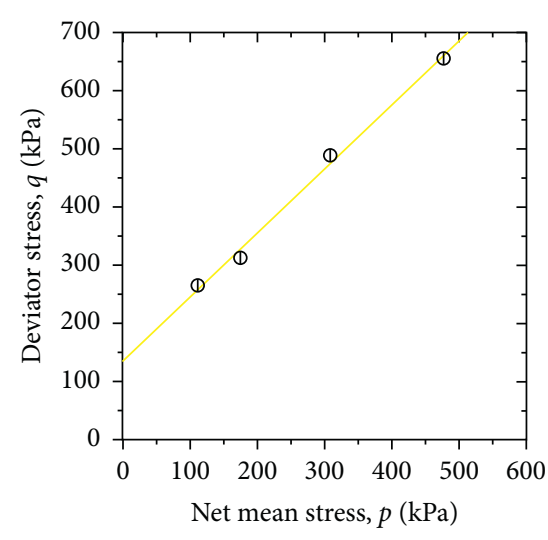

(1) ST1

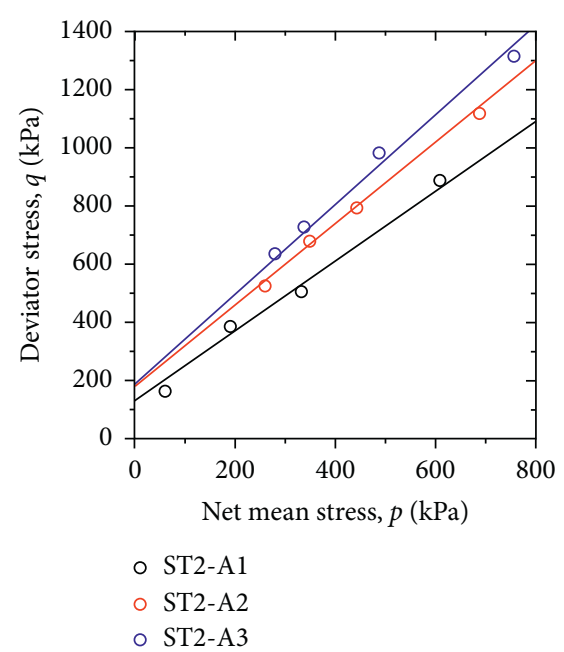

(b)

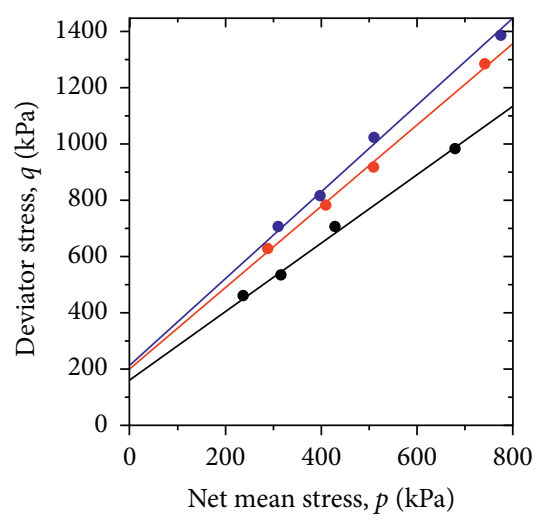

- ST2-B1

- ST2-B2

- ST2-B3

(a)

FIgUre 10: Critical state lines on $q$-p planes. (a) Undisturbed sample; (b) remoulded samples containing 3\% nanosilica; (c) remoulded samples containing $5 \%$ nanosilica.

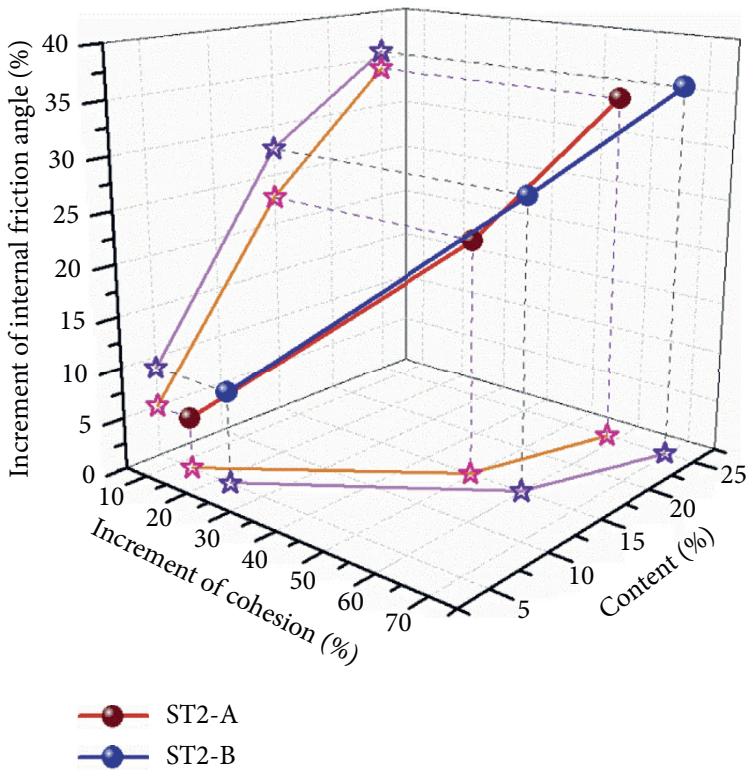

FIGURE 11: The increment of cohesion and internal friction angle of grouting samples compared with the undisturbed sample.

Results show that the slope of Lvliang Airport is stable and this new material has a good effect on the slope reinforcement so far. In the future, we will also need to test and analyze the same parameters, such as compactness and bonding degree of the grouting material, after a certain period of time. Moreover, necessary numerical simulation to further examine the stability of the slope will be the focus of our next research.

\section{Analysis}

According to the field investigation and the results of the triaxial test, the failure process of the unsaturated loess slope before filling fissure and the mechanism of stabilizing the slope after injection are further interpreted as follows. The study area is characterized by steep terrain and concentrated rainfall (Figure 4), which create favourable condition for the occurrence of landslides [45]. The rainfall-induced floods caused lateral erosion and downward erosion on both sides of the Maqun gully in Figure 2, which lead to the redistribution of the internal stress of the slope [46]. Then, a strong tensile stress zone is formed at the top of the slope, and horizontal deformation occurs gradually towards the free face due to the loss of support. When the tensile stress exceeds the strength limit of the soil element, the loess will undergo tensile failure. Consequently, discontinuous transverse tensile fissures will appear at the top of the slope, which speed up the infiltration of rain deeper into the weak plane. Field survey found that the slip zone of old loess landslide is located in Lishi loess, where the loess is loose and 


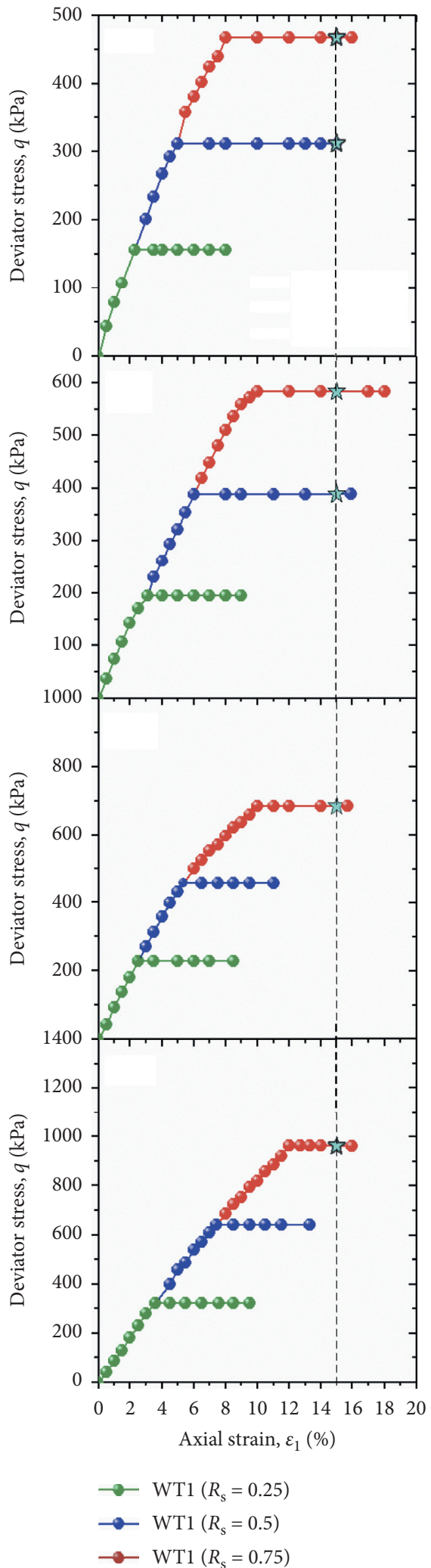

(a)

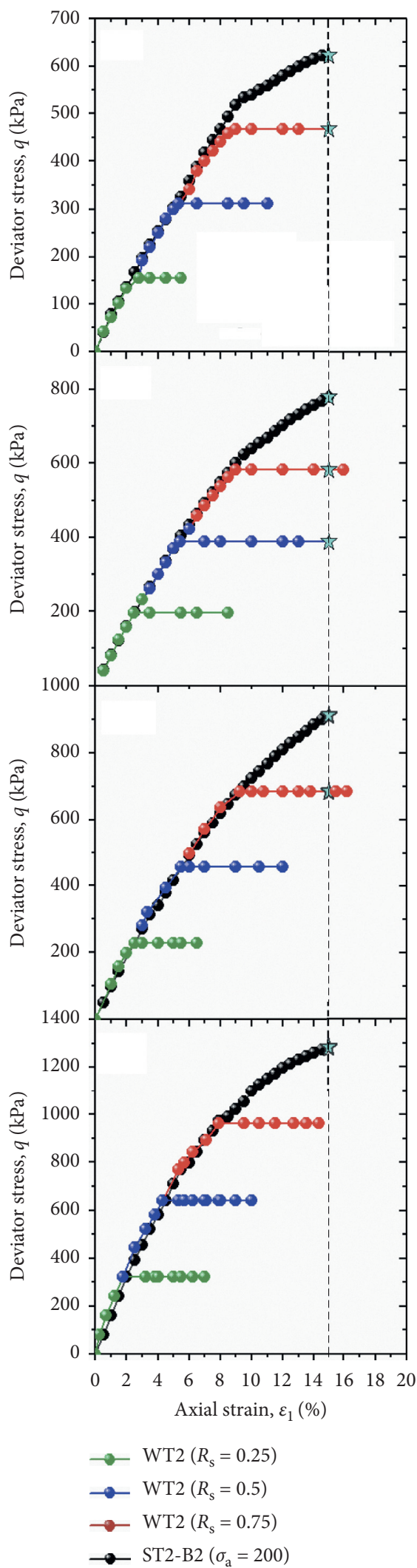

(b)

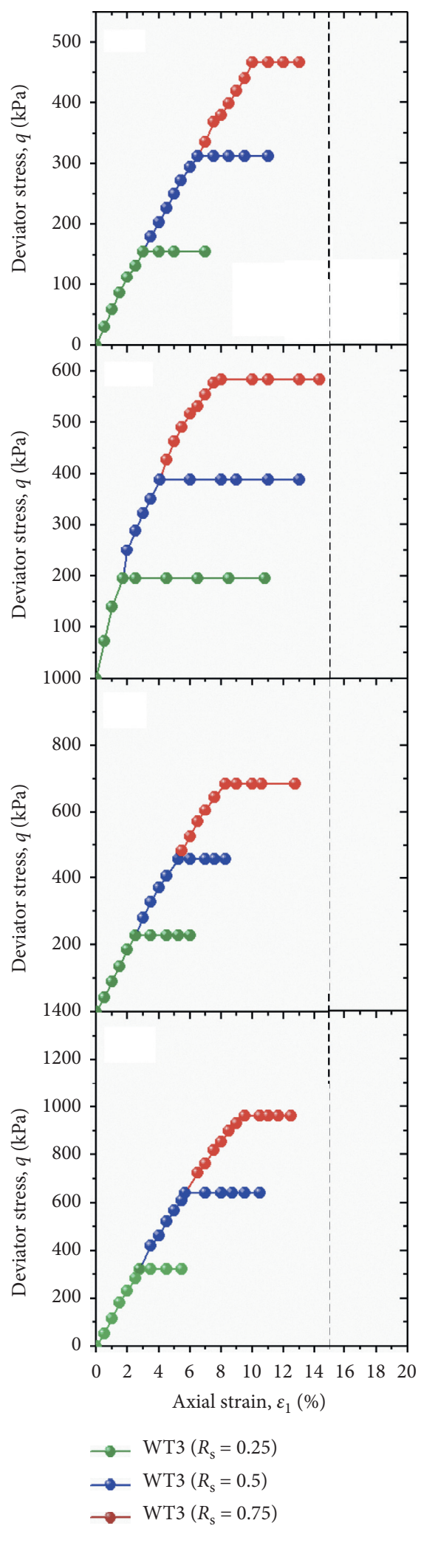

(c)

Figure 12: Deviator stress-axial strain curves from WT. The content of filling materials: (a) 10\%; (b) 15\%; (c) 20\%. The net confining pressures: $50 \mathrm{kPa}, 100 \mathrm{kPa}, 200 \mathrm{kPa}$, and $400 \mathrm{kPa}$. 


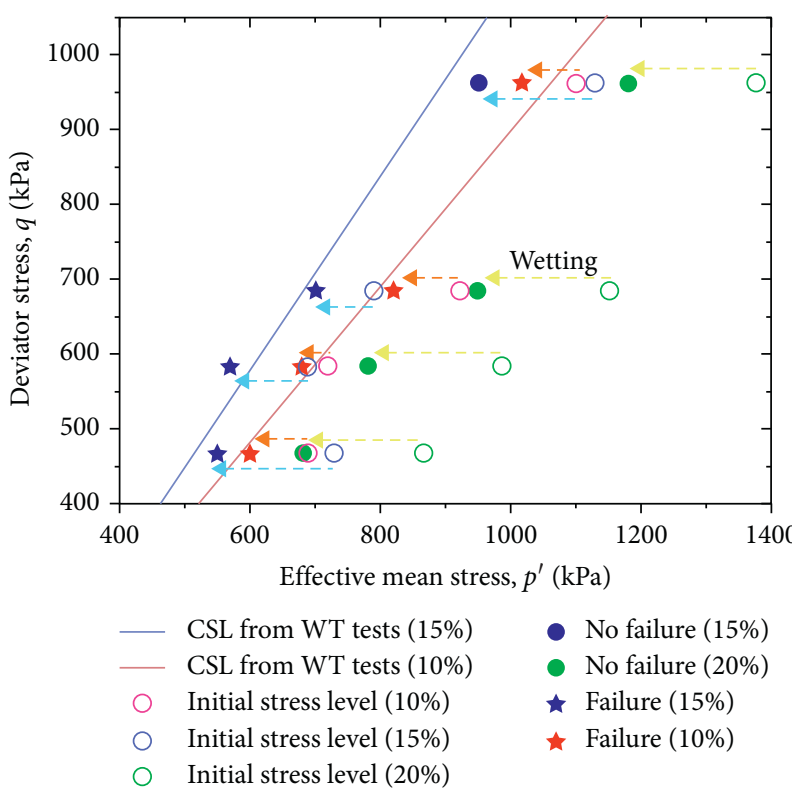

FIgURE 13: Critical state lines on $q-p^{\prime}$ planes from WT.

TABLE 5: The grouting parameters of field tests.

\begin{tabular}{lccccccc}
\hline $\begin{array}{l}\text { Test } \\
\text { time } \\
(\mathrm{d})\end{array}$ & $\begin{array}{c}\text { Grouting } \\
\text { material shape }\end{array}$ & $\begin{array}{c}\text { Shrinkage } \\
(\%)\end{array}$ & $\begin{array}{c}\text { Permeability } \\
\text { coefficient } \\
\left(10^{-9} \mathrm{~cm} \cdot \mathrm{s}^{-1}\right)\end{array}$ & $\begin{array}{c}\text { Compressive } \\
\text { strength }(\mathrm{MPa})\end{array}$ & $\begin{array}{c}\text { Flexural } \\
\text { strength } \\
(\mathrm{MPa})\end{array}$ & $\begin{array}{c}\text { Bond } \\
\text { strength } \\
(\mathrm{kPa})\end{array}$ & $\begin{array}{c}\text { Average } \\
\text { thickness of } \\
\text { grout }(\mathrm{mm})\end{array}$ \\
\hline 28 & Lamelliform & 0.04 & 1.847 & 15.7 & 4.6 & $\begin{array}{c}\text { Filled } \\
\text { area }(\%)\end{array}$ \\
\hline
\end{tabular}

have good permeability. Under the effect of rainfall wetting, the pore water pressure inside the soil increases, while the matric suction decreases. And the antishear force provided by the soil itself cannot resist the sliding force composed of the gravity of the slope and water pressure. Consequently, the stress state of the soil in the slip zone first reaches its ultimate strength, and the soil fail eventually, appearing intermittent fissures. In the absence of human intervention, under the continuous action of rainfall, the fissures in the slip zone inside the slope may connect and accelerate the revival of the old loess landslide.

In this paper, the landslide is to be treated by grouting into the fissures inside and at the top of the slope (Figure 14). The dense structure of the grouting material is beneficial to water insulation, and the test results suggest that the shear strength of remoulded loess is higher than that of the undisturbed. On the one hand, filling materials are injected into the tensile fissures at the top of the slope. Then, the slurry penetrates into the interior along the fissure, filling the fissures and penetrating into the surrounding soil, which can resist the tensile stress on the top of the slope and reduce the pore water pressure. On the other hand, drilling and then grouting into the internal slip zone of the slope. Under the effect of high-pressure jet, the natural structure of the loess changes, and a series of physical and chemical reactions occur between the loess and the stabilizer. Consequently, new structure is formed to resist the sliding force of the slope, thus achieving the purpose of treating landslide [47].

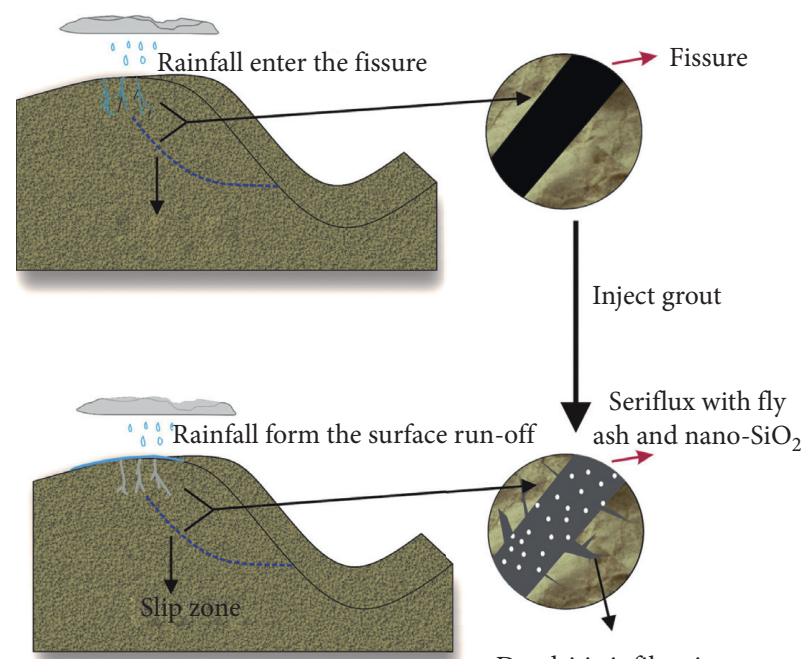

Dendritic infiltration

Figure 14: Schematic diagram of fissures in Lvliang Airport: (a) before grouting; (b) after grouting.

The key is to select the appropriate content of filling materials to stabilize the slope, achieving the optimal reinforcement effect at a lower input cost. Considering that it is time consuming and labor intensive to choose a large number of materials with different ratios for tests, the dichotomy in mathematics was introduced to find the threshold of the material content, which can be described as 
follows. Firstly, three discrete points were selected on a wide range for the triaxial shear test; then, the relationship between strength parameters and filling materials content was shown through the line graph, and the turning point (15\%) was found when the test curves significantly changed from steep to gentle, indicating that the improvement is limited. The variations of the cohesion and internal friction angle with filling material content of the remoulded (containing $5 \%$ nana- $\mathrm{SiO}_{2}$ ) and the undisturbed are presented in Figure 15. These two curves fit into cubic equations:

$$
\begin{aligned}
& C=-0.00211 a^{3}+0.0128 a^{2}+2.64867 a+59.3, \\
& \Phi=-0.00068 a^{3}+0.0156 a^{2}+0.439 a+28.2,
\end{aligned}
$$

where $a$ is the filling material content. It could be predicted that the threshold must be near the turning point, taking it as the benchmark, the upper and lower two intervals were divided in half. On this basis, three kinds of ratios of the stabilizer were selected for the WT test. All data points corresponding to the failure appeared to lie on a straight line in Figure 13. And the equation of the lines can be expressed generically as follows:

$$
q=M p^{\prime}+H
$$

This also suggests that the loess failure behaviour induced by wetting could be described by the linear form of the Mohr-Coulomb strength theory:

$$
\sin \Phi=\frac{\left(\sigma_{1}-\sigma_{3}\right)}{(\sigma 1+\sigma 3+2 c \cot \Phi)}
$$

The deviator stress and mean stress are defined as $q=\sigma_{1}-\sigma_{3}$ and $p=\left(\sigma_{1}+2 \sigma_{3}\right) / 3$, respectively. And thus equation (4) can be rewritten as follows:

$$
q_{f}=3 p \sin \Phi+2 c \cos \Phi-\sigma_{3} \sin \Phi .
$$

When the stabilizer content reaches the threshold value $a_{0}$, the slope just reaches the critical state of failure under the effect of rainfall wetting. At this point, the loess just reaches the saturated state and the matric suction decreases to $0 \mathrm{kPa}$. And thus equation (3) can be rewritten as follows:

$$
q_{f}=M_{0} p+H_{0} .
$$

Comparing equations (4) and (5), thus slope (M) and intercept $(H)$ can be expressed as the functional forms of cohesion, internal friction angle, and confining pressure:

$$
\begin{aligned}
& M=3 \sin \Phi, \\
& H=2 c \cos \Phi-\sigma_{3} \sin \Phi .
\end{aligned}
$$

It can be found that the slope and intercept of CSL induced by wetting are influenced by the confining pressure $\sigma_{3}$ and the material content $a$, such as equations (1), (2), (7), and (8). When the loess element is at a high stress level and the content of filling material is not more than $a_{0}$, the loess element may fail under the action of rainfall, which is shown by CSL with small slope in Figure 13. The results of WT tests

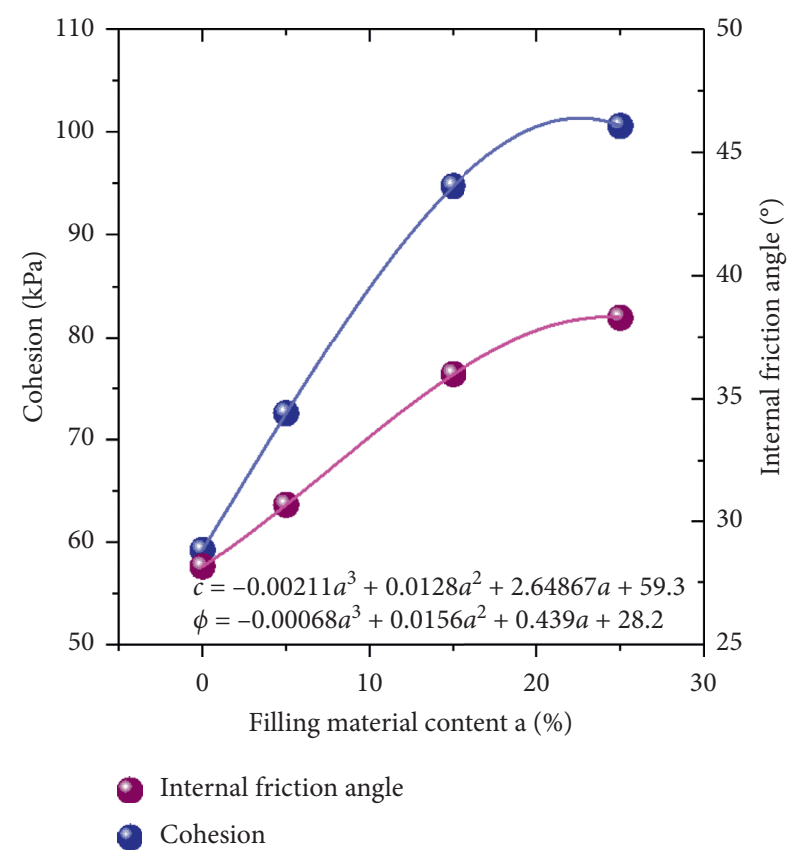

FIGURE 15: Filling material content against cohesion and internal friction angle from ST.

show that when the material content reached $a_{0}, H_{0}>H_{15}$, and thus $15 \%<a_{0}<20 \%$, where $H_{15}$ is the slope of CSL from the sample which contains $15 \%$ stabilizer.

Based on the slope of Lvliang Airport, the advantage of this paper is to narrow down the research scope through reasonable methods, fewer test times, and triaxial tests that simulate the process of rainfall wetting on the real slope and to select the most suitable grouting material content threshold, thus carrying out field grouting tests. According to the method introduced in this paper, the interval of the threshold can be further narrowed to meet the requirements of the application.

\section{Conclusions}

In this paper, the feature of potential slip zone inside the slope of Lvliang Airport was revealed through field investigation. And a series of laboratory tests were performed on specimens taken from the slip zone, including triaxial shear tests at constant matric suctions and wetting tests at constant deviator stresses, in order to simulate the stress state of the slope under the effect of rainfall wetting before and after grouting and study the effect of material content on the slope stability. The conclusions are drawn as follows.

The increase of confining pressure is beneficial to the compaction of loess and the formation of secondary structures. Under the same confining pressure, the structural strength of the remolded is obviously better than that of the undisturbed, which reflects the enhancement of the deformation resistance of the loess due to the filling material. Moreover, nanosilica is more conducive to the improvement. This is mainly because that nanosilica fills the pores in 
the solidified loess and fly ash aggregates, forming a denser structure.

The critical state lines (CSL) of the undisturbed and the remoulded determined by ST were unique in the $q-p^{\prime}$ plane. Compared with the undisturbed, the cohesion and the internal friction angle of the remoulded were significantly improved and were proportional to the amount of filling material. However, the test curves significantly changed from steep to gentle, showing that the improvement is limited.

Under the action of rainfall, the failure behaviour of the slope along the wetting path after filling fissures depends on the stress level and the content of filling materials. At a low stress level, the slope can remain stable after filling fissures, while at a high stress level, the slope may fail due to insufficient stabilizer content. There must exist a threshold of the stabilizer content, which can stabilize the slope at a lower input cost. The threshold was found to be between $15 \%$ and $20 \%$.

To prevent the revival of the old loess landslide in Lvliang Airport under the action of wetting, the method is suggested, including grouting into the fissures on the top of the slope and the internal potential slip zone. Filling fissures on the top of the slope can effectively reduce the pore water pressure caused by rainwater infiltration and resist the tensile stress. Meanwhile, grouting on the potential slip zone can promote the formation of a new denser structure between the loess and slurry, thus resisting the sliding force of the slope, so as to treat the landslide.

So far, field grouting tests have been carried out in the Lvliang Airport. Results indicated that this new material has a good effect on the slope reinforcement. More test methods will be used to examine the slope stability in the future.

\section{Data Availability}

The data used to support the findings of this study were supplied by Jiading Wang under license and so cannot be made freely available. The data used to support the findings of this study are available from the corresponding author upon request.

\section{Conflicts of Interest}

The authors declare that there are no conflicts of interest regarding the publication of this paper.

\section{Acknowledgments}

This study was supported and funded by the National Natural Science Foundation of China (Grant nos. 41630639 and 41941017), National Key Research and Development Plan (Grant no. 2018YFC1504703), and Natural Science Foundation of Shaanxi Province (Grant no. 2020JQ-584).

\section{References}

[1] X. Pei, F. Zhang, W. Wu, and S. Liang, "Physicochemical and index properties of loess stabilized with lime and fly ash piles," Applied Clay Science, vol. 114, pp. 77-84, 2015.
[2] J. Wang, D. Zhang, N. Wang, and T. Gu, "Mechanisms of wetting-induced loess slope failures," Landslides, vol. 5, no. 16, pp. 937-953, 2019.

[3] H. Qiu, Y. Cui, Y. Pei et al., "Temporal patterns of nonseismically triggered landslides in Shaanxi province, China," Catena, vol. 187, Article ID 104356, 2020.

[4] Q. Ran, Y. Hong, W. Li, and J. Gao, "A modelling study of rainfall-induced shallow landslide mechanisms under different rainfall characteristics," Journal of Hydrology, vol. 563, pp. 790-801, 2018.

[5] E. W. Brand, "Landslides in southeast Asia, a state-of the art report," in Proceedings of the International Symposium of Landslides, Toronto, Canada, 1984.

[6] A. B. Fourie, "Predicting rainfall-induced slope instability," in Proceedings of the Institution of Civil Engineers Geotechnical Engineering, London, UK, 1996.

[7] A. Ali, J. Huang, A. V. Lyamin et al., "Simplified quantitative risk assessment of rainfall-induced landslides modelled by infinite slopes,” Engineering Geology, vol. 179, pp. 102-116, 2014.

[8] L. Xu, F. C. Dai, X. B. Tu et al., "Occurrence of landsliding on slopes where flowsliding had previously occurred: an investigation in a loess platform, north-west China," Catena, vol. 104, pp. 195-209, 2013.

[9] R. P. Orense, S. Shimoma, K. Maeda, I. Towhata, and A. Fourie, "Instrumented model slope failure due to water seepage," Journal of Natural Disaster Science, vol. 1, no. 26, pp. 15-26, 2004.

[10] P.-T. Yeh, K. Z.-Z. Lee, and K.-T. Chang, "3D Effects of permeability and strength anisotropy on the stability of weakly cemented rock slopes subjected to rainfall infiltration," Engineering Geology, vol. 266, Article ID 105459, 2020.

[11] Y.-L. Chen, G.-Y. Liu, N. Li, X. Du, S.-R. Wang, and R. Azzam, "Stability evaluation of slope subjected to seismic effect combined with consequent rainfall," Engineering Geology, vol. 266, Article ID 105461, 2020.

[12] J. Zhang, D. Zhu, and S. Zhang, "Shallow slope stability evolution during rainwater infiltration considering soil cracking state," Computers and Geotechnics, vol. 117, Article ID 103285, 2020.

[13] M. Rosone, M. Ziccarelli, A. Ferrari, and C. A. Farulla, "On the reactivation of a large landslide induced by rainfall in highly fissured clays," Engineering Geology, vol. 235, pp. 20-38, 2018.

[14] J. Wang, Y. Xu, Y. Ma, S. Qiao, and K. Feng, "Study on the deformation and failure modes of filling slope in loess filling engineering: a case study at a loess mountain airport," Landslides, vol. 12, no. 15, pp. 2423-2435, 2018.

[15] J. B. Jamora, S. E. L. Gudia, A. W. Go, M. B. Giduquio, and M. E. Loretero, "Potential $\mathrm{CO}_{2}$ reduction and cost evaluation in use and transport of coal ash as cement replacement: a case in the Philippines," Waste Management, vol. 103, pp. 137-145, 2020.

[16] S. Abbas, M. A. Saleem, S. M. S. Kazmi, and M. J. Munir, "Production of sustainable clay bricks using waste fly ash: mechanical and durability properties," Journal of Building Engineering, vol. 14, no. 14, pp. 7-14, 2017.

[17] C. Heidrich, H. J. Feuerborn, and A. Weir, "Coal combustion products-a global perspective," in Proceedings of the World of Coal Ash Conference, pp. 22-25, Copenhagen, Denmark, May 2013.

[18] F. Haining, "Test research on engineering characteristic of flyash," Rock and Soil Mechanics, vol. 5, no. 23, pp. 579-582, 2002.

[19] D. K.R. Gupta, "Performance of concrete with fly ash and kaolin inclusion," Imperial Journal of Interdisciplinary Research, vol. 7, no. 2, 2016. 
[20] D. Wang, P. Yang, P. Hou, L. Zhang, Z. Zhou, and X. Cheng, "Effect of $\mathrm{SiO}_{2}$ oligomers on water absorption of cementitious materials," Cement and Concrete Research, vol. 87, pp. 22-30, 2016.

[21] Q. Lv, C. Chang, B. Zhao, and B. Ma, "Loess soil stabilization by means of $\mathrm{SiO}_{2}$ nanoparticles," Soil Mechanics \& Foundation Engineering, vol. 6, no. 54, pp. 409-413, 2018.

[22] R. Kong, B. Yan, J. Xu, Z. Shi, and X. Lin, "Physical homogenization and chemical stability of nano- $\mathrm{SiO}_{2}$ treated loess," Soil Mechanics and Foundation Engineering, vol. 58, no. 5, 2019.

[23] Z. Rong, W. Sun, H. Xiao, and G. Jiang, "Effects of nano-SiO particles on the mechanical and microstructural properties of ultra-high performance cementitious composites," Cement and Concrete Composites, vol. 56, pp. 25-31, 2015.

[24] G. L.D. Stephan, "The influence of nano-silica on the hydration of ordinary portland cement," Journal of Materials Science, vol. 2, no. 47, pp. 1011-1017, 2012.

[25] A. Tomar, T. Sharma, and S. Singh, "Strength properties and durability of clay soil treated with mixture of nano silica and polypropylene fiber," Materials Today: Proceedings, vol. 26, 2020.

[26] J. M. Sarli, F. Hadadi, and R. Bagheri, "Stabilizing geotechnical properties of loess soil by mixing recycled polyester fiber and nano- $\mathrm{SiO}_{2}, "$ Geotechnical and Geological Engineering, vol. 38, no. 2, 2019.

[27] I. Chang, J. Im, A. K. Prasidhi, and G.-C. Cho, "Effects of xanthan gum biopolymer on soil strengthening," Construction and Building Materials, vol. 74, pp. 65-72, 2015.

[28] H. Fatehi, S. M. Abtahi, H. Hashemolhosseini, and S. M. Hejazi, "A novel study on using protein based biopolymers in soil strengthening," Construction and Building Materials, vol. 167, pp. 813-821, 2018.

[29] Y. Zhang, A. E. Johnson, and D. J. White, "Freeze-thaw performance of cement and fly ash stabilized loess," Transportation Geotechnics, vol. 21, Article ID 100279, 2019.

[30] G. Li, X. Hou, Y. Mu, W. Ma, and Y. Mao, "Engineering properties of loess stabilized by a type of eco-material, calcium lignosulfonate," Arabian Journal of Geoences, vol. 22, no. 12, 2019.

[31] X. Xiong, Z. Shi, Y. Xiong, M. Peng, X. Ma, and F. Zhang, "Unsaturated slope stability around the three gorges reservoir under various combinations of rainfall and water level fluctuation," Engineering Geology, vol. 261, Article ID 105231, 2019.

[32] S. Zhang, X. Zhang, X. Pei et al., "Model test study on the hydrological mechanisms and early warning thresholds for loess fill slope failure induced by rainfall," Engineering $\mathrm{Ge}$ ology, vol. 258, Article ID 105135, 2019.

[33] I. Arya, I. Wiraga, and I. Suryanegara, "Effect of cement injection on sandy soil slope stability, case study: slope in petang district, badung regency," Journal of Physics: Conference Series, vol. 953, Article ID 012103, 2018.

[34] T. Kamei, A. Ahmed, and T. Shibi, "The use of recycled bassanite and coal ash to enhance the strength of very soft clay in dry and wet environmental conditions," Construction and Building Materials, vol. 38, pp. 224-235, 2013.

[35] D. Milledge, D. Bellugi, and J. Mckeanet, "A multidimensional stability model for predicting shallow landslide size and shape across landscapes," Journal of Geophysical Research, vol. 11, no. 119, pp. 2481-2504, 2014.

[36] M. MukhlisinK and N. Khiyon, "The effects of cracking on slope stability," Journal of the Geological Society of India, vol. 6, no. 91, pp. 704-710, 2018.
[37] J. D. Wang, T. F. Gu, and N. Q. Wang, "Geological features of loess landslide at lüliang airport and its 3D stability analysis," Rock and Soil Mechanics, vol. 7, no. 34, pp. 2009-2016, 2013.

[38] C. L. Chen, P. Gao, and J. Tang, "Structural quantitative parameter of intact loess with different water contents triaxial stress condition," Chinese Journal of Rock Mechanics \& Engineering, vol. 11, pp. 2313-2319, 2006.

[39] Y. S. Luo, "Variation characteristics of soil structure and structural constitutive relation of unsaturated loess under static and dynamic complex stress conditions," Chinese Journal of Rock Mechanics \& Engineering, vol. 11, no. 23, pp. 1959-1958, 2004.

[40] Q. Y. Mu, C. Zhou, and C. W. W. Ng, "Compression and wetting induced volumetric behavior of loess: macro- and micro-investigations," Transportation Geotechnics, vol. 23, Article ID 100345, 2020.

[41] J. M. X. Li, "Effects of carbonate on the structure and properties of loess and the corresponding mechanism: an experimental study of the malan loess, Xi'an area, China," Bulletin of Engineering Geology and the Environment, vol. 7, no. 78, pp. 1-12, 2019.

[42] A. Adami and A. Rinaldi, "The influence of amorphous silica on the aging of a remoulded loessial soil," Soils and Foundations, vol. 3, no. 57, pp. 315-326, 2017.

[43] A. O. Adetukasi, F. George, I. Adebakin, and O. Omokungbe, "Strength characteristics of fibre-reinforced concrete containing nano-silica," Materials Today: Proceedings, 2020.

[44] M. Nuth, L. Laloui, and J. W. Hilf, "Effective stress concept in unsaturated soils: clarification and validation of a unified framework," International Journal for Numerical and Analytical Methods in Geomechanics, vol. 7, no. 32, pp. 771-801, 2008.

[45] P. Sun, G. Wang, L. Z. Wu, O. Igwe, and E. Zhu, "Physical model experiments for shallow failure in rainfall-triggered loess slope, northwest China," Bulletin of Engineering Geology and the Environment, vol. 6, no. 78, pp. 4363-4382, 2019.

[46] X. Qiao, X. Li, Y. Guo, and S. Ma, "In-situ experimental research on water scouring of loess slopes," Environmental Earth Sciences, vol. 77, no. 11, p. 417, 2018.

[47] Y. M. Tang, Q. Xue, Z. G. Li, and W. Feng, "Three modes of rainfall infiltration inducing loess landslide," Natural Hazards, vol. 1, no. 79, pp. 137-150, 2015. 